\title{
SNAP Expansions and Participation in Government Safety Net Programs
}

\author{
Jeehoon $\operatorname{Han}^{*}$
}

October, 2016

\begin{abstract}
Gauging the efficacy of safety net programs requires a good understanding of how the interactions between them affect the total benefits and costs of any given policy change. This paper investigates the interactions between health and nutritional assistance programs such as Medicaid, SNAP, WIC, and school lunch programs. Since 1999, states have been given much more flexibility to operate SNAP, and many states have expanded eligibility to include households with income and resources above the existing federal limits for SNAP. Exploiting this variation in SNAP eligibility across states and over time, I find strong evidence of program interactions: when a state moves from the federal rule to the most extensive SNAP eligibility rule, enrollment in free school lunch increases by 4 percentage points. I estimate that the federal government spends an additional 37 cents on the school lunch program for each dollar spent on SNAP due to the expansion. However, expanded eligibility for SNAP leads to a significant decrease in private insurance coverage for both adults and children, which is not fully explained by an increase in Medicaid enrollment. Exploring potential channels through which SNAP expansions affect participation in other safety net programs, I find evidence that automatic eligibility, and a reduction in employment, play a role in program interactions.
\end{abstract}

\footnotetext{
* Department of Economics, University of Notre Dame. Email: jhan4@ nd.edu. I would like to thank Jim Sullivan, Bill Evans, and Abigail Wozniak for their guidance and support. I am also grateful to Forrest Spence, Felix Zhiyu Feng, Qian Wei, and seminar participants at the University of Notre Dame for their useful comments.
} 


\section{Introduction}

A substantial fraction of low-income households participate in multiple programs as target income groups among safety net programs often overlap (Gothro and Trippe 2010; Edelstein et al., 2014; Bartfeld, 2015; Moffitt, 2015). For example, 72\% of SNAP (Supplemental Nutritional Assistance Program) families received at least one other transfer program benefit in 2010 (Moffitt, 2015). This overlap implies that there is the potential for program incentives and benefits to affect the use of other programs. As a result, the welfare implications of a policy change hinge on its interactions with other safety net programs. Moreover, program interactions lead to budgetary spillovers (Clemens, 2015). For example, to the extent that enrolling in SNAP has positive spillovers onto participation in Medicaid, which is jointly funded by states and the federal government, SNAP expansions could incur additional, unintended state expenditures. Understanding the links between safety net programs, therefore, is essential for producing comprehensive estimates of total benefits and costs of a policy change.

Grasping the mechanisms through which safety net programs interplay with each other is important because different policy implications can be drawn depending on the mechanisms underlying the program spillovers. If expanded SNAP eligibility increases take-up of other social benefits through reducing work incentives and thus earnings, policy makers may consider imposing work requirements for SNAP benefits or increasing deductions from earned income as countable income (currently 20\%) to encourage work. However, if program spillovers occur because of an increase in program awareness or reduced application costs, it has an implication for outreach design, encouraging eligible individuals to enroll in social programs.

In this study, I investigate mechanisms for program interactions and their consequences in the context of health and nutrition programs. Specifically, I quantify the impact of SNAP expansions on participation in health and other nutrition programs such as Medicaid, the school lunch program, and WIC

(The Special Supplemental Nutrition Program Women, Infants, and Children) and explore the mechanisms underlying the linkage between them. SNAP is one of the largest U.S. safety net programs, 
providing $\$ 69.7$ billion in benefits to 45.8 million people in 2015. Participation in SNAP has dramatically increased during the last decade, arguably caused by both recent economic downturns and changes in program parameters such as an increase in the benefit level and eligibility expansions (Mulligan 2012; Ganong and Liebeman 2015; Zilliak 2015).

An important challenge with estimating the impact of SNAP on participation in other programs is that unobserved factors which affect SNAP eligibility and take-up may also affect the eligibility and takeup of other social programs. For example, a family member's job loss, which entails losing employerbased health insurance, may affect Medicaid participation as well as SNAP eligibility through household income changes. To address this concern, I take advantage of recent state level SNAP eligibility expansions. SNAP eligibility was, for the most part, set by federal rules prior to 1999. Since then, however, the USDA has allowed states to expand SNAP eligibility through a policy called Broad-Based Categorical Eligibility (BBCE). States have increasingly adopted BBCE programs over the last decade; 41 states had adopted BBCE by 2013. Exploiting variation in SNAP eligibility stemming from this policy change, I construct an index, reflecting the extensiveness of SNAP eligibility at the state-year level between 1997 and 2013.

Using this variation in eligibility and data from the Survey of Income and Program Participation (SIPP), I find strong evidence of interactions between health and nutrition programs. Expanded SNAP eligibility not only increased the SNAP participation rate but also increased free school lunch enrollment. In particular, a change in eligibility criteria from the federal rules to the most extensive SNAP rules increased the SNAP participation rate by 6 percentage points and free school lunch participation rate by 4 percentage points. Extrapolating from this analysis, I estimate that the federal government spent an additional 37 cents on the school lunch program per dollar spent on SNAP due to the SNAP expansion. I also find a substantial decrease in private health insurance for both adults and children, which is not fully explained by an increase in Medicaid enrollment as a result of SNAP expansions.

SNAP expansions could affect participation in other programs through several possible channels. One channel involves changes in labor supply: people may respond to expanded SNAP eligibility by 
adjusting their work effort and income. The income change, in turn, can affect eligibility for other programs. The second channel by which SNAP expansions could affect take-up of other programs is through bundled eligibility. Eligibility rules for free school lunch and WIC do not differ across states. However, since SNAP households are automatically eligible for these programs, expanded SNAP eligibility indirectly alters their eligibility thresholds. Third, during the SNAP application process, people may learn about eligibility and application rules for other safety net programs. Finally, participation in SNAP may reduce costs involved in applying for other programs, increasing their take-up. I examine the relative importance of potential mechanisms underlying program spillovers by leveraging variation in the type of information SNAP applicants receive, and the application costs for free school lunch benefits, which are generated by policy changes in SNAP and the school lunch program.

My findings reveal that bundled eligibility—SNAP recipients are automatically eligible for free school lunch and WIC benefits - and a decrease in labor supply along the extensive margin are important factors that explain program spillovers. The labor supply response also leads to a decrease in health insurance coverage since unemployment often entails losing employer-based health insurance. Although bundled eligibility appears to mechanically affect participation in related programs, it can also influence take up of other social benefits through heightened awareness or reduced application costs regarding relevant programs. Testing the independent roles of application costs and program awareness, I find suggestive evidence that a reduction in application costs increases free lunch enrollment, while the role of information in explaining the spillover effect is minimal. Taken together, my results demonstrate that there is a strong linkage in participation across nutrition and health programs, and this interaction likely affects the welfare and budgetary consequences of the SNAP expansion.

My findings also have implications for program take-up literature. My results show that newly eligible SNAP households respond to financial incentives such as benefit size and application costs since bundled eligibility and direct certification systems improve enrollment in free school lunch. By contrast, I find little evidence that providing a brochure or referral information to SNAP households enhances enrollment in WIC and free lunch. This may be because SNAP households are already aware of these 
programs or because the brochure does not contain enough information about the program rules or enrollment process. It is important to note, however, that my analysis is based on one specific information intervention (providing a brochure and referral information), and therefore, I cannot rule out the possibility that information through other sources, including communication with the case workers in SNAP enrollment process, increases program take-up.

The remainder of the paper is as follows: Section 2 provides a review of relevant literature. In section 3, I present a brief overview of the relevant welfare programs, introduce the institutional background on SNAP, and discuss the potential channels through which programs interact with each other. Section 4 describes the data used for the analysis and presents the empirical strategy and identification assumptions. Section 5 presents my results on the linkage between health and nutrition programs. In Section 6, I quantify the relative importance of potential mechanisms underlying program interactions. The final section provides some concluding remarks.

\section{Related Literature}

My paper is related to several strands of research. First, I complement a body of literature that documents interactions between safety net programs. Program spillovers are studied in the context of a variety of safety net programs such as Medicaid, TANF, EITC, Housing Assistance, and Unemployment Insurance (UI). For example, several papers examine the effect of Medicaid on other programs such as AFDC/TANF, SNAP, and SSI (Supplemental Security Income) using rollout of Medicaid and expansions of Medicaid eligibility. These papers found that Medicaid expansion lead to reductions in SSI enrollment (Yelowitz, 2000), increases in SNAP enrollment (Yelowitz, 1996) and AFDC participation (Yelowitz, 1995; Decker and Selck, 2012) while others found no relationship between Medicaid and AFDC (Ham and Shore-Sheppard, 2005). More recently, Baicker et al. (2014) use a randomized experiment in Oregon and find little effect of Medicaid on participation in TANF or disability insurance, but they find increases in SNAP enrollment. 
Despite a large body of evidence on program interactions, little is known about how SNAP—one of the largest and fastest growing welfare program in the U.S - affects participation in other safety net programs. This is in part because, until quite recently, key parameters in SNAP such as eligibility rules and benefit levels exhibited relatively limited variation across states over time (Hoynes and Schanzenbach, 2015). My paper fills the gap in the literature by providing some of the first evidence on the effects of SNAP on use of other programs. ${ }^{1}$

Second, I contribute to the literature studying the factors underlying incomplete social benefit take-up (Currie, 2006). This literature has largely focused on testing a potential channel affecting participation in one program. A number of studies have shown that transaction costs (Blank and Ruggles, 1996; Currie and Grogger, 2001; Bitler et al., 2003; Hanratty, 2006; Aizer, 2007), program awareness (Daponte et al., 1999; Kling et al., 2012; Bhargava and Manoli, 2015), social networks (Bertrand et al., 2000; Duflo and Saez, 2003; Chetty et al., 2013; Dahl et al., 2014), and other behavioral factors such as procrastination, and framing of the message (Bertrand et al., 2006; Hastings and Tejeda-Ashton, 2008) affect the decision to participate in public programs, while several studies find little effect of these factors on program participation (Ebenstein and Stange, 2010; Jones, 2010). This study provides new evidence on the relative importance of multiple factors affecting program take-up such as program awareness and application costs in the context of multiple welfare programs.

Third, my analysis contributes to the literature on the labor supply effect of SNAP (Fraker and Moffitt, 1988; Hagstrom, 1996; Keane and Moffitt 1998; Hoynes and Schanzenbach, 2012). Unlike most previous studies that show little work incentives, I find evidence that SNAP expansions lead to a decline in employment; specifically the decline is concentrated on two-parent households. This finding may reflect that the SNAP expansion targets a relatively high income group (income between 100-200\% FPL). This group may face a different labor market and work incentives compared to those with income below

\footnotetext{
${ }^{1}$ I am aware of only one study that examines the effect of SNAP on enrollment in other programs. Lindner and Nichols (2012) use state policies for multiple programs including SNAP, TANF, and UI as instruments for SNAP participation and find a positive effect of SNAP participation on SSI applications among job losers. However, their specifications do not include state fixed effects, suggesting that the estimates are potentially biased by state characteristics correlated with both state policy variables and application for SSI.
} 
the poverty line. The large reduction in employment may also reflect limited employment opportunities in the recent recession during which most SNAP expansions were implemented.

Lastly, I contribute to the literature on BBCE policies. My findings regarding the positive effect of BBCE expansions on SNAP participation rate are consistent with prior research (Mulligan 2012; Ganong and Lieberman 2013; Olds 2016; Han 2016). I extend Han (2016), who analyzes the effect of BBCE expansions on material well-being of low-income households, by estimating behavioral and budgetary effects of the policy change.

\section{Background on Health and Nutrition Programs}

\subsection{Program Overview}

In this section, I provide a brief description of the major health and nutrition programs that I study in this paper: Medicaid, SNAP, WIC, and the school lunch program. Specifically, I present program goals, rules, and statistics with an emphasis on how these programs might connect with each other.

1) Food and nutrition programs

SNAP. SNAP (Supplemental Nutritional Assistance Program) is the largest food program providing nutritional support to low-income people. In 2015, SNAP served more than 45 million people at a cost of $\$ 74$ billion. Under the federal rules, to be income eligible for SNAP, households must have a gross income below $130 \%$ of the Federal Poverty Line (FPL) and net income (income after deductions) needs to fall below the poverty line. In addition to the income eligibility criteria, households need to meet an asset limit of $\$ 2,250$. More lenient income/assets threshold requirements are applied if the household has an elderly or disabled member. Households in which all members receive a cash benefit such as SSI or TANF benefits are categorically eligible for SNAP and are exempt from both the SNAP income and asset tests. $^{2}$

\footnotetext{
${ }^{2}$ Since gross income includes cash benefits from other programs such as TANF and Social Security, there is a tradeoff between cash benefits and SNAP benefits that depends on states' generosity with cash benefits. I do not focus on
} 
WIC. The Special Supplemental Food Program for Women, Infants, and Children (WIC) offers nutritious foods, nutrition counseling, health screenings, and nutrition education for pregnant women, postpartum women, infants, and children up to age five. In 2015, WIC served 8 million participants at a cost of $\$ 6.2$ billion. Since WIC is not an entitlement program, federal funds may not be enough to serve all eligible applicants. ${ }^{3}$ Households with gross income up to $185 \%$ of the FPL are income eligible for WIC, and participants in another welfare program such as TANF, Medicaid, or SNAP are automatically income eligible for WIC. In addition to the income requirement, a WIC applicant has to be assessed as nutritionally at risk — having medical-based conditions such as anemia and underweight, or dietary-based conditions (e.g., a poor diet)— to be eligible for WIC.

School Lunch Program. The national school lunch program (NSLP) is a federal food program providing low-cost or free lunches to children. The NSLP served about 30.5 million children each school day in 2015, and around $73 \%$ of NSLP participants received free/reduced-price meals, while around $27 \%$ of NSLP participants paid a full price. Children from families with incomes at or below 130\% FPL are eligible for free meals, and those with incomes between $130 \%$ and 185\% FPL are eligible for reduced-price meals. A child who lives in a household that receives SNAP benefits automatically qualifies for free school meals. Schools operating the NSLP receive cash subsidies based on the number of meals served. To claim reimbursement, the schools are generally required to determine annually the eligibility for free and reduced-price meals and count the number of meals served daily by type (free, reduced-price, and paid). However, some schools do not collect applications, nor do they record the categories of meals for reimbursement under the special provisions referred to as Provision 1, Provision 2, Provision 3 and the Community Eligibility Provision (CEP). These provisions allow schools in high

the effect of SNAP expansions on take up of TANF benefits since most of my sample (households with income between $100 \%-200 \%$ FPL) do not qualify for TANF.

${ }^{3}$ When WIC funding is limited, Infants and pregnant and breastfeeding women have a higher priority than children do. In recent years, however, funding has been sufficient to serve all eligible applicants (Oliverira and Frazao, 2015). 
poverty areas to provide free meals to all students without requiring applications every year, leading to a reduction in administrative costs and improvement in access to school meals for low-income students. ${ }^{4}$

\section{2) Health Programs}

Medicaid and CHIP (Children's Health Insurance Program) provide health care assistance for low-income individuals and children, respectively. As of December 2015, about 73 million low-income people were covered by Medicaid or CHIP, and the total spending amounted to about $\$ 532$ billion in 2015. Both Medicaid and CHIP are financed jointly by the federal government and the states. Specifically, the federal share of Medicaid (CHIP) expenditure in each state depends on the state's per capita income relative to the national average with the minimum amount of $50 \%(65 \%)$. Because of this funding structure, Medicaid and CHIP play an important role in both state and federal budgets. Flexibility for states in determining Medicaid/CHIP parameters, including eligibility rules, leads to wide variation in eligibility requirements across groups and states. In particular, Medicaid income eligibility levels for infants range from $144 \%$ to $380 \%$ FPL and Medicaid income eligibility levels for parents range from $18 \%$ to $221 \%$ FPL in 2015.

Since eligibility limits for both SNAP and Medicaid are set by states, one could be worried that states that expanded eligibility for SNAP simultaneously changed Medicaid eligibility, confounding the effect of SNAP expansions. To address this concern, I include in my specifications three indicators for whether children are eligible for Medicaid, whether children are eligible for CHIP, and whether parents are eligible for Medicaid.

Because of the similarities in the eligibility and application processes between Medicaid and SNAP, states have implemented a number of policies to improve integration between the two programs and reduce administrative burdens on both applicants and caseworkers. For instance, a majority of states allow applicants to file a single application form and attend a single interview for both programs. Moreover, states have increasingly adopted the Express Lane Eligibility (ELE) policy in which Medicaid

\footnotetext{
${ }^{4}$ For example, In SY 2013-2014, 11 states participated in the CEP.
} 
agencies can use SNAP records to enroll uninsured SNAP children into Medicaid and automatically renew Medicaid eligibility.

\subsection{SNAP Eligibility Expansion}

Under the traditional categorical eligibility rules, households receiving cash assistance from TANF, SSI, or General Assistance (GA) bypass the income and resource tests and are deemed eligible for SNAP benefits. However, since 1999, states are allowed to confer categorical eligibility for SNAP to households receiving TANF or maintenance-of-effort (MOE) funded non-cash benefits. Under these broad-based categorical eligibility (BBCE) rules, states can apply less strict eligibility limits for these noncash benefits and expand eligibility for SNAP. Moreover, BBCE rules can apply to anyone who receives a simple brochure or referral information on state assistance programs as long as the information is funded through TANF/MOE.

As the number of states that expand the BBCE programs increases, so does the number of households who are categorically eligible for SNAP. In particular, 41 states (including the District of Columbia) had implemented BBCE programs by 2013, compared to only 8 states adopting BBCE in 2001 . Among the 41 states that implemented BBCE, 24 states set the gross income threshold higher than 130\% of FPL and 31 states eliminated the net income test. For example, in 2010, Florida relaxed the gross income limit to $200 \%$ of the FPL and eliminated the net income and asset limits for all households. For details on states' SNAP eligibility criteria, see Appendix Table 1.

In addition to BBCE programs, states have implemented a number of policies that may simplify the administration and improve take-up of SNAP. Important rule changes include: reducing income reporting requirements between certification periods, eliminating face-to-face interview at enrollment and renewal, withdrawing short recertification intervals of three months or less, restoring SNAP eligibility for qualified immigrants who were rendered ineligible by welfare reform in 1996, operating call centers, and 
using Electronic Benefit Transfer (EBT) cards to issue benefits. To account for any potential impacts of these policies on program participation, I control for these policies in my specifications.

\subsection{Potential Channels for Program Interactions}

In this subsection, I present four main channels through which expanded eligibility for SNAP might influence participation in other safety net programs: labor supply, bundled eligibility, application costs, and program awareness.

$<$ Figure 1 here>

Labor Supply: More generous eligibility criteria may change work incentives and thus income, which, in turn, can affect eligibility for other programs. Figure 1 illustrates the implications of expanded SNAP eligibility on labor supply using a simple static model. For simplicity, I assume that every household that meets the gross income test receives SNAP benefits. The budget constraint faced by households living in a state with federal SNAP rules has a notch at the gross income limit (130\% FPL), as represented by line ABCDE. Expanding eligibility to the most extensive BBCE rules (200\% FPL) eliminates the notch on the budget constraint, ${ }^{5}$ altering the budget constraint to line ABFE. Two types of labor supply responses operate in opposite directions. While households with higher income may reduce their labor supply to participate in SNAP (person A), those with lower income may increase their work effort (person B), resulting in ambiguous net effects on labor supply. When I consider multiple program participation, the qualitative predictions for labor supply responses do not change as shown in Appendix Figure $1 .^{6}$

Bundled Eligibility: Another mechanism through which SNAP expansions affect participation in other programs is automatic eligibility. For example, the NLSP is a federal program and the eligibility rules do not vary across states. However, categorical eligibility combined with variation in SNAP expansions

\footnotetext{
${ }^{5}$ In practice, households with high net income might receive zero benefits although they pass the gross income test. This is because SNAP benefits are calculated by the maximum benefits minus $30 \%$ of net income.

${ }^{6}$ The magnitude of labor supply responses, however, depends on the benefit size and the awareness of other programs. For instance, when SNAP and the school lunch program are jointly considered (Panel A of Appendix Figure 1), compared to when SNAP is considered alone, the SNAP eligibility expansion may generate greater incentives to change work effort because households that receive SNAP also qualify for free school lunch.
} 
indirectly generates variation in eligibility for free school lunch. For people who did not participate in the school lunch program because their perceived price of school lunches were expensive, eligibility for free school lunch through the SNAP expansions is likely to encourage take-up of the school lunch program.

Program Awareness: Given that the households made eligible for SNAP as a result of the BBCE expansions have relatively high income, they may have limited knowledge about state assistance programs. Therefore, participation in SNAP may increase awareness of eligibility rules/benefits for other programs that they would not know otherwise. Moreover, states that expanded eligibility for SNAP through $\mathrm{BBCE}$ also provided a brochure or referral information on the state assistance programs during the application process. Through this information, SNAP households may learn about other programs, increasing their take-up of other programs.

Application Costs: The BBCE expansions may also affect participation in other programs by lowering costs of applying for other programs. For instance, households that are eligible only for WIC may determine that the costs associated with applying for the benefits are larger than the value of benefits, so they do not enroll. When these households also become eligible for SNAP, the increased total benefits may outweigh the application costs involved, improving the take-up rate of both SNAP and WIC benefits. Moreover, categorical eligibility, which simplifies the application and eligibility determination process, reduces application costs and thus facilitates program participation. I will investigate each of these potential mechanisms in detail below.

\section{Identifying the Linkage between Health and Nutrition Programs}

\subsection{Data and Sample Restrictions}

My analysis draws on data from the 1996, 2001, 2004, and 2008 panels of the Survey of Income and Program Participation (SIPP), covering the period from 1997 to 2013. The SIPP is a longitudinal survey, following 20,000-50,000 households in each panel over a period of 2-4 years. The SIPP interviews households every four months and collects detailed information on demographics, labor force 
status, income, and program participation over the previous four months. Therefore, it is well-suited for the analysis of program linkages and labor supply. I aggregated individual level data to household level data since SNAP eligibility is determined at a household income level. Similarly, monthly data is aggregated to the year level. ${ }^{7}$ In this setting, therefore, a household is considered participating in SNAP in a given year if any member of the household reports SNAP benefits in any of the last 12 months. I define the main sample as single-family households with children that have gross income between $100 \%$ of the FPL and $200 \%$ of the FPL because this income group is most likely to be affected by an expansion of eligibility requirements, and because programs such as WIC and the school lunch program are relevant only for households with children. I further exclude households that moved between states during the reference period to avoid welfare migration problems (see Method Appendix for details on the sample construction).

$<$ Table 1 here>

Table 1 shows the program participation rate and key characteristics for low-income households (income 100\%-200\% FPL) and higher income households (income 200\%-300\% FPL) which are less likely to be affected by SNAP expansions. The first column suggests that a large fraction of low-income households participate in health and nutrition programs. For example, about one-fourth of low-income households participated in SNAP at least one month in the last 12 months, and more than 50\% of lowincome households received free school lunch and Medicaid benefits. Households with income between $200 \%$ and $300 \%$ FPL (column 2) have much lower participation rates in SNAP and other programs compared to low-income households, yet more than $20 \%$ of this group received WIC benefits, free school lunch, or Medicaid benefits at some point in the last 12 months. The relatively high participation rate among the higher income group could be explained by eligibility misclassification or simplified reporting/recertification requirements for the benefits. First, there can be a misclassification of eligible households because the actual eligibility is determined by gross monthly income, while I use average

\footnotetext{
${ }^{7}$ For the years 2000 and 2008, the SIPP collects data covering less than a 9-month period. Therefore, these two years are dropped from my sample period.
} 
monthly income for the last year to impute eligibility for SNAP. ${ }^{8}$ Second, health and nutrition programs typically have a 6 month or longer certification period during which participants can maintain their eligibility regardless of an increase in household income.

\subsection{Methodology}

To examine the effect of SNAP eligibility on program participation, one might consider using the following approach:

$$
Y_{i s t}=\alpha+\beta_{1} E L I G_{i s t}+\theta_{s}+\mu_{t}+\gamma X_{i s t}+\delta Z_{s t}+\varepsilon_{i s t}
$$

where $Y_{\text {ist }}$ is outcome variables such as benefit receipt from safety net programs and labor supply for household $i$, living in state $s$, in year $t$, and $E L I G_{i s t}$ is an indicator for whether a household is eligible for SNAP. The parameters $\theta_{s}$ and $\mu_{t}$ are state and year fixed effects, respectively, which account for permanent state characteristics and population-wide trends. $X_{\text {ist }}$ includes the demographic characteristics of households listed in Table 1 and Medicaid/CHIP eligibility. $Z_{s t}$ includes state characteristics such as the annual state unemployment rates, the state level poverty rates, other changes in SNAP beside BBCE, and other policy parameters. ${ }^{9}$

The primary concern with this estimation approach is that unobservable factors that influence the decision to enroll in other programs may be associated with SNAP eligibility, leading to biased estimates. For example, a family member's illness may affect not only SNAP eligibility through household income changes, but also the take-up of Medicaid. To address this issue, I use a measure of simulated eligibility which reflects the extensiveness of SNAP eligibility in the given state and time period. In other words, I estimate:

\footnotetext{
${ }^{8}$ To determine WIC eligibility, states can use either income during the past 12 months or the current month income. ${ }^{9}$ SNAP policy variables include the fraction of SNAP dollars provided via the EBT, indicators for whether call centers are available, whether any working households face a short recertification periods (3 months or less), whether noncitizen adults are eligible for SNAP benefits, whether noncitizen children are eligible for SNAP benefits, whether applications could be submitted online, whether the face-to-face interview is waived at enrollment, renewal, or both, and whether the state has a simplified reporting system for SNAP. Other policy variables include minimum wage levels, TANF maximum benefit levels, EITC phase-out rates, and an indicator for whether the state has its own EITC.
} 


$$
Y_{i s t}=\alpha+\beta_{1} \operatorname{SIMELIG} G_{s t}+\theta_{s}+\mu_{t}+\gamma X_{i s t}+\delta Z_{s t}+\varepsilon_{i s t}
$$

To construct a measure of simulated eligibility, I first establish a baseline sample including households with children that would be eligible under the most extensive BBCE rules, but ineligible for the federal rules in each year. ${ }^{10}$ Simulated eligibility is then calculated as the fraction of this national sample that would be eligible for SNAP under eligibility rules in each state and month. In other words, simulated eligibility for state $s$ in month $t$ is calculated as:

$$
\text { SIMELIG } G_{s t}=\frac{\# H H \text { eligible under the SNAP rules } s_{S t}-\# H H \text { eligible under the federal rules } t_{t}}{\# H H \text { eligible under the most extensive BBCE rules } t_{t}-\# H H \text { eligible under the federal rules } t_{t}}
$$

I take an average of this simulated eligibility over the 12 reference months because, in my setting, the unit of observation is at the household-year level. Therefore, simulated eligibility is coded as 0 for the households in a state using the federal SNAP rules and 1 for the households in a state using the most extensive BBCE rules (see Method Appendix for further discussion of the simulated eligibility measure). This simulated eligibility measure accounts for biases stemming from unobserved household characteristics since it varies only with the state SNAP rules in the given time period.

$<$ Figure 2 here>

Figure 2 shows the trends in simulated eligibility (left panel) and SNAP enrollment (right panel) between high and low simulated eligibility states from 1997 to 2013. States are partitioned into two groups based on the level of simulated eligibility in 2013: "High simulated eligibility" states reach simulated eligibility greater than or equal to 0.5 by 2013 and "Low simulated eligibility" states have simulated eligibility smaller than 0.5 for the entire period between 1997 and 2013. Panel A shows that there were only small differences in the level of simulated eligibility between high and low simulated eligibility states until 2007. Since then, however, high simulated eligibility states see a sharp increase in simulated eligibility, consistent with the fact that most states expand eligibility for SNAP during the Great Recession. These trends in simulated eligibility broadly match those in the actual SNAP participation rate

\footnotetext{
${ }^{10}$ For years 2006, 2007, 2012, and 2013, household asset information is not available in the SIPP data. I use the baseline sample in 2005 (2011) for calculation of simulated eligibility in 2006 and 2007 (2012 and 2013).
} 
(right panel) as high simulated eligibility states see a greater increase in SNAP enrollment than low simulated eligibility states after 2007.

<Table 2 here>

One potential concern to this estimation approach is that states may expand SNAP eligibility when they experience economic downturns, leading to a spurious correlation between eligibility expansions and the outcomes. To explore this issue, I regress a state's BBCE status (or level of simulated eligibility) on a state's contemporaneous unemployment rates and lagged unemployment rates. ${ }^{11}$ The results in columns 1-2 of Table 2 show that although states with higher contemporaneous unemployment rates are somewhat more likely to implement BBCE and have higher simulated eligibility, the effect is small in magnitude. In particular, the point estimate in column 1 indicates that a 1 percentage point increase in the current unemployment rate is associated with only a 6.5 percentage point increase in the probability of adopting BBCE. In the recent recession period (columns 3 and 4), the contemporaneous employment rate has a smaller effect on the decision to implement BBCE and the extensiveness of SNAP eligibility, although the lagged effect of the unemployment rate is larger than that with the entire sample period.

To alleviate concerns with factors related to labor market conditions, which may influence both the state's SNAP eligibility expansion and program participation, I include the level of the state's contemporaneous unemployment rate as well as the 1-year and 2-year lagged unemployment rates in my main specifications. However, there may still be state-specific shocks other than eligibility expansions that impact the decision to enroll in SNAP and other programs. Therefore, I also implement a triple difference specification, which utilizes within-state variation in SNAP eligibility across income groups. Specifically, I estimate the following triple difference specification in which lower-middle-income households (gross income between 200\% and 300\% FPL) that are less likely to be affected by the SNAP expansion serves as a comparison group:

\footnotetext{
${ }^{11}$ This analysis also includes controls for state political environment such as the fraction of the state House/Senate that is Democrat and whether the governor of the state is Democrat.
} 


$$
\begin{aligned}
Y_{i s t} & =\alpha+\beta_{1} \text { LOWINC }_{i t} \cdot \text { SIMELIG }_{s t}+\beta_{2} \text { LOWINC }_{i t}+\beta_{3} \text { SIMELIG }_{s t}+\theta_{s} \cdot \mu_{t} \\
& +\operatorname{LOWINC}_{i t} \cdot \theta_{s}+\operatorname{LOWINC}_{i t} \cdot \mu_{t}+\operatorname{\sigma LOWINC}_{i t} \cdot Z_{s t}+\theta_{s}+\mu_{t}+\gamma X_{i s t}+\delta Z_{s t}+\varepsilon_{i s t}
\end{aligned}
$$

LOWINC $C_{i t}$ is an indicator variable that is equal to 1 if the household has gross income between $100 \%$ and $200 \%$ of the FPL and 0 if the household has gross income between $200 \%$ and $300 \%$ of the FPL. ${ }^{12}$ This specification also controls for unobservable state-year shocks that equally affect both income groups, $\theta_{s} \cdot \mu_{t}$, as well as group-specific state and year fixed effect, $\operatorname{LOWINC}_{i t} \cdot \theta_{s}$ and $\operatorname{LOWINC}_{i t} \cdot \mu_{t}$. To allow the effect of state policies and labor market conditions on outcomes to be different for low-income households and lower-middle-income households, I also control for an interacted set of state variables and the indicator for low-income households, $\operatorname{LOWINC} C_{i t} \cdot Z_{s t}$.

In this specification, the main coefficient of interest is $\beta_{1}$, which identifies the effect of SNAP expansions under the assumptions that 1) state-specific shocks that have a differential effect for lowincome households and lower-middle-income households are unrelated to eligibility expansion and 2) the SNAP expansion does not affect the comparison group. ${ }^{13}$

\section{The Effect of SNAP Expansions on Program Participation}

\subsection{Direct Effect on SNAP participation}

$<$ Table 3 here>

Before studying the program spillover effects of the SNAP expansions, I first examine their direct effect on SNAP enrollment in Table 3. Specifically, I estimate equation (2) with SNAP participation as

\footnotetext{
${ }^{12}$ As shown in Table 1, the demographic characteristics of the samples illustrate that the higher income households are more educated, more likely to have their own home, and are more likely to have a larger number of employed adults, as would be expected given their higher income. Controlling for education level, marital status, and employment status of the head of household, however, I find that occupation distributions of the two groups become similar, and thus they are likely to face similar labor market opportunities.

${ }^{13}$ In practice, however, there are at least two reasons why the comparison group could be influenced by the SNAP expansion. The first is misclassification of the treatment and comparison groups and the second is endogeneity of income. For example, some households whose yearly income is above 200\% FPL may experience seasonal or temporary income decreases and qualify for SNAP. In this case, the triple difference estimates will understate the effect of eligibility expansions on SNAP enrollment. In contrast, some households among the higher income group could reduce their income below 200\% FPL to receive SNAP benefits, and therefore be in the low-income group.
} 
dependent variable. Column 1 presents estimates for all households with children, column 2 restricts the sample to WIC eligible households - households with children under age 5, and column 3 restricts the sample to the school lunch eligible households-households with children aged between 5-17. The results in column 1 show clear evidence that eligibility expansions increase SNAP participation for the targeted income group, consistent with prior work (Olds, 2016; Han, 2016). The difference-in-difference estimate in Panel A suggests a statistically significant 6 percentage point increase in SNAP enrollment for households with children, as a result of a change from the federal rules to the most extensive BBCE rules, which was the actual change for ten states. The estimates for WIC and the school lunch eligible households are qualitatively similar (columns 2 and 3). Panel B shows that the effect of SNAP expansion on SNAP participation is robust to using the triple-difference specification, though the estimates for WIC eligible households (column 2) are not statistically significant. Since the results are broadly consistent across specifications, I discuss results using the main specification (difference-in-difference) in the remainder of the paper unless the corresponding triple difference results are noticeably different.

\subsection{Evidence on Program Spillovers}

\section{1) Food and Nutrition Programs}

$<$ Table 4 here $>$

I next examine whether the expanded SNAP eligibility affects participation in WIC and the school lunch program in Table 4. In general, the results in Table 4 show that expanded SNAP eligibility has noticeable effects on participation in other food and nutrition programs. Specifically, for WIC eligible households (column 1), expanding SNAP eligibility from the federal rule to the most extensive BBCE rules increases WIC participation by 9.6 percentage points, an increase of $19.6 \%$. The next two columns report estimates on free school lunch and reduced-price lunch enrollment. As discussed earlier, households with income between 130\%-185\% FPL qualify for reduced-price lunch regardless of the SNAP expansion, and a large fraction of this income group becomes eligible for free school lunch through categorical eligibility when 
SNAP eligibility is expanded. Thus, one might expect that the SNAP expansion increases participation in free school lunch, but not in reduced-price lunch. Indeed, the results in column 2 indicate that SNAP expansions lead to a marginally significant increase of 4 percentage points in free school lunch enrollment, while the effect on reduced-price lunch participation (column 3) are negative but statistically insignificant. The triple difference specification (Panel B) yields qualitatively similar results, but the effect on free school lunch becomes larger and more precisely estimated, and the effect on reduced-price lunch becomes positive.

To estimate the potential budgetary effects of expanding SNAP eligibility, I multiply the estimated effects of SNAP expansions on free school lunch enrollment, 4 percentage points, by the average simulated eligibility level from 2001 to 2013, 0.26, and by the average number of households with school-aged children and income between $100 \%$ and 200\% FPL during this period, 5.7 million. $^{14}$ This back-of-the-envelope calculation indicates that, in each year between 2001 and 2013, 67 thousand households participated in free school lunch due to SNAP expansions. By multiplying this by the annual value of free school lunch per household, ${ }^{15}$ I estimate that the federal government spent $\$ 988$ million on the school lunch program over 2001-2013 as a result of the SNAP expansion. A similar calculation for SNAP costs indicates that the government spent $\$ 2.7$ billion over 2001-2013 due to expanded SNAP eligibility. Taken together, I estimate that the government spent additional 37 cents on the school lunch program for each dollar spent on SNAP benefits due to expanded SNAP eligibility. ${ }^{16}$

\section{2) Health Insurance Coverage}

$<$ Table 5 here $>$

\footnotetext{
${ }^{14}$ The number of households with school-aged children and income between 100\% and 200\% FPL is estimated from the March CPS and Census data over 2001-2013.

${ }^{15}$ Following Bartfeld (2015), I value school lunch meals at the federal reimbursement rate paid to school (\$2.70 in $2010)$ and assume that recipients receive free school lunch over the entire school year (220 days). This benefit level (\$594) is then multiplied by the average number of school-aged children in a household in my sample, 2 , to calculate the total annual value of free school lunch per household.

${ }^{16}$ When using the triple difference specification, the estimated cost from the spillover effects on participation in the school lunch program is 70 cents for each dollar spent on SNAP benefits.
} 
The SNAP expansion may also influence Medicaid or CHIP through a number of channels mentioned above. In Table 5, I examine the impacts of SNAP expansions on health insurance coverage. Specifically, I focus on three types of health insurance coverage: any insurance (private or Medicaid, which from here always includes CHIP), private insurance, and Medicaid. Because Medicaid eligibility criteria are much more limited for adults than for children, the effect of SNAP expansions on health insurance coverage may differ between adults and children. Therefore, I explore the effect of SNAP expansions on health insurance coverage for adults (columns 1-3) and children (columns 4-6) separately. For adults, I find that SNAP expansions lead to a statistically significant 3.8 percentage point decline in any insurance coverage (column 1). This is due to a substantial reduction in private health insurance (column 2), which is not accompanied by an increase in Medicaid enrollment (column 3). In contrast, for children, expanded SNAP eligibility has a small and insignificant effect on any health insurance coverage (column 4). This is because a sizeable reduction in private insurance (column 5) is mitigated by rising Medicaid enrollment (column 6), though the effect on Medicaid is not statistically significant. Taken together, results in Table 5 suggest that a significant share of households in my sample drop their private insurance in response to SNAP expansions. While some children transition to Medicaid, there is little evidence of increases in adult Medicaid enrollment, resulting in an increasing number of uninsured adults.

There are at least two channels through which expanded SNAP eligibility decreases private health insurance coverage. First, working adults may reduce their work effort in response to the SNAP expansion which, in some cases, entails losing their employer-based private health insurance. Another potential explanation is that newly SNAP eligible households may become aware that a member of the household is eligible for Medicaid in the SNAP application process and thus drop their private insurance. In this case, the relatively small increase in Medicaid enrollment (column 3) may be explained by CHIP waiting periods - children must remain uninsured prior to enrolling in CHIP in many states-or conditional coverage - eligible individuals may enroll in public insurance only after they need medical care (Cutler and Gruber, 1996; Marton and Yelowiz, 2015). To explore whether the small impact of the SNAP expansion on Medicaid enrollment is due to waiting periods, I examine the effect of 1-year lagged 
simulated eligibility on current health insurance coverage in Panels C and D. The results show a somewhat larger increase in children's Medicaid enrollment, but the estimates are still statistically insignificant. ${ }^{17}$

Although the mechanisms behind the effects of the SNAP expansions on health insurance coverage are yet unclear, a significant reduction in private insurance for both adults and children together with the modest increase in child Medicaid enrollment suggests that parental insurance decisions are tied to their children's insurance options. This is in line with the findings of a previous study (Koch, 2015) that documented a large decrease in private health insurance among adults when their children became eligible for Medicaid.

\section{Mechanisms Underlying Program Interactions}

The results presented above provide strong evidence of program spillovers as a result of SNAP expansions. Now I consider mechanisms underlying the spillover effects. I examine the relative importance of potential mechanisms for program spillovers by estimating the labor supply response to the SNAP expansions and exploiting variation in the type of information SNAP applicants receive and the application costs for free school lunch benefits, which are generated by policy changes in SNAP and the school lunch program.

1) Labor Supply

As discussed earlier, expanded eligibility for SNAP leads to ambiguous effects on labor supply. While some lower income households face incentive to increase their labor supply as they can maintain eligibility for SNAP with higher earnings, higher income households may reduce their work effort to receive SNAP benefits.

$<$ Table 6 here>

\footnotetext{
${ }^{17}$ The first stage estimates corresponding to the specifications in Panel C and Panel D are 0.074 (0.025) and 0.064 (0.022), respectively. State clustered standard errors are in parentheses.
} 
Table 6 displays the impact of SNAP expansions on whether the household head was ever employed during the last 12 months (column 1), the head's average weekly hours of employment (column 2), the head's average weekly hours conditional on work (column 3), and the head's average monthly earnings (column 4). Overall, I find a large decline in the head's employment and earnings although the estimates are imprecise in many cases. The point estimate in column 1 of Panel A indicates that a change from the federal rule to the most extensive BBCE rules causes a statistically insignificant decline in the head's employment of 2.2 percentage points. In the triple difference specification (Panel B) the estimate is larger in absolute value (5.1 percentage points) and is statistically significant. ${ }^{18}$ The results in column 2 suggest that there is a reduction in the head's weekly hours worked due to the SNAP expansions, which could be caused by a reduction in the extensive or intensive margin of work. To investigate changes in the intensive margins of work, in column 3, I exclude households that were never employed during the last 12 months. I find no evidence that household heads reduce work effort along the intensive margin. Therefore, a decrease in the head's earnings (column 4) occurs mainly through a reduced employment.

One concern with these estimates of the effect of labor supply is that the baseline sample is chosen based on the average income over the last 12 months, which is a function of the outcome variables: the head's employment and hours worked during the period. Therefore, to the extent that labor supply responses change the composition of the sample, the estimated effects on labor supply will be biased. To address this issue, in Appendix Table 1, I construct an alternative sample based on the first four months' income and use information on labor supply and program participation in the remaining eight months. In this way, I include households that experience an increase (or a decrease) in household income due to changes in their work behavior in the sample. The results again suggest that the SNAP expansion reduce the head's employment (column 1). By contrast, I find suggestive evidence that employed household heads increase work hours (column 3).

\footnotetext{
${ }^{18}$ Recall that the estimated first stage coefficients were relatively small -6 percentage points in the difference-indifference specification and 6.6 percentage points in the triple difference specification. Therefore, the corresponding treatment-on-treated estimates on employment for those who enrolled in SNAP are substantial.
} 
The labor supply responses to SNAP expansions depend on whether individuals in a household freely change their work efforts. Households with more than one earner may be able to adjust labor supply more easily. In Panels C-F of Table 6, I explore labor supply responses for married couples and single parents separately. I find a large negative impact of the SNAP expansions on the head's employment and earnings for married couples (Panels C and D). In particular, the results in column 1 of Panel D show a statistically significant 7.3 percentage point reduction in the head's employment rate as the eligibility criteria changes from the federal rules to the most extensive BBCE rules. The impact on the head's earnings is also negative and statistically significant (column 4 of Panels C and D). By contrast, for single parents (Panels E and F), the impact of the SNAP expansions on the head's employment and earnings are minimal. Therefore, the negative employment effects of the SNAP expansion are driven primary by a reduced employment among two-parent households that account for a large fraction (63\%) of the baseline sample.

Previous studies have generally found little impact of the food stamp program on labor supply (Fraker and Moffitt, 1988; Hagstrom 1996; Keane and Moffitt 1998). One exception is Hoynes and Schanzenbach, 2012) who use the county-level variation in the food stamp program rollout and find a significant reduction in the employment rate and hours worked for single mothers. For married-couple households, however, they found no effect on labor supply. There are several reasons why my findings differ from prior studies on the effects of SNAP on labor supply. First, I focus on a relatively higher income group (gross income between 100\% and 200\% FPL) compared to average SNAP recipients (gross income about 57\% FPL in 2010). Households in my sample are more educated and more likely to be employed, suggesting that they face a different labor market and work incentives compared to those with income below the poverty line. ${ }^{19}$ Second, most of SNAP eligibility expansions occurred during the Great Recession. During a recession when there are limited job opportunities, unemployed individuals may put less effort into searching for a job with SNAP benefits than they would without, leading to a longer

\footnotetext{
${ }^{19}$ The fact that higher income households are more likely to work also reflects a larger scope for reduction in labor supply.
} 
unemployment spell. Third, given that previous estimates of the labor supply effect of SNAP are mostly based on changes in SNAP parameters in the 1970s and 1980s, the difference in results may come from changes in demographics, women's labor force participation, and other safety net programs such as Medicaid, TANF, and EITC over the last three decades.

\section{2) Application Costs}

Another plausible channel through which SNAP expansions increase enrollment in other programs is application costs: participation in SNAP could reduce costs associated with applying for other social benefits. To explore the role of application costs in program spillovers, I leverage additional variation in the application process for free school meals across states over time. SNAP participants can be certified for free school meals by 1) filing an application form for the school lunch program (but they can skip the "income" section by reporting their SNAP case numbers), 2) forwarding letters from SNAP agencies about their SNAP receipt to the Local Education Agency (LEA), ${ }^{20}$ or 3) direct certification (DC) which requires no action as the state (or LEA) agencies match SNAP records against the student enrollment list. ${ }^{21}$ Therefore, among the three methods, DC involves the lowest application costs for free school meals. In SY 2004-2005, about 56\% of LEAs directly certified categorical eligible students. ${ }^{22}$ Since then, the number of LEAs that have direct certification systems gradually increased, and in SY 2013-2014, 93\% of LEAs directly certify SNAP participants (Moore et al., 2015). ${ }^{23}$ I utilize state-level variation in the fraction of LEAs that directly certify categorical eligible students to examine the impact of an application cost reduction on participation in free/reduced-price school lunch. Specifically, I include two variables in the baseline specification: an indicator for whether a state has a high fraction of LEAs using DC (85\% or more, which is the percent of LEAs that use DC in the median state during the sample

\footnotetext{
${ }^{20}$ This option has not been available since SY 2012-2013.

${ }^{21}$ Parents or guardians of children receive a notification of their children's eligibility for free school lunch.

${ }^{22}$ Special provision LEAs that provide free meals to all students without collecting applications are excluded from the count of the total number of LEAs.

${ }^{23}$ Although the Child Nutrition and WIC Reauthorization Act of 2004 mandated direct certification with SNAP for all LEAs by SY 2008-2009, 13 states still had a direct certification rate lower than 90\% in SY 2013-2014.
} 
period) and the interaction between the high DC state indicator and simulated eligibility. ${ }^{24}$ In other words, I estimate the following specification:

$$
\begin{aligned}
Y_{i s t} & =\alpha+\beta_{1} H I G H D C_{s t} \cdot S_{I M E L I G}+\beta_{2} H I G H D C_{s t}+\beta_{3} S_{I M E L I G} G_{s t} \\
& +\theta_{s}+\mu_{t}+\gamma X_{i s t}+\delta Z_{s t}+\varepsilon_{i s t}
\end{aligned}
$$

In this specification, the coefficients on SIMELIG $G_{s t}$ capture the effect of the SNAP expansion on participation in the free/reduced-lunch program for low DC states, while the coefficients on $H I G H D C_{s t}$. SIMELIG $G_{\text {st }}$ measure the impact of the SNAP expansion on free/reduced lunch enrollment for high DC states relative to low DC states. ${ }^{25}$

\section{$<$ Table 7 here>}

Table 7 reports the results from this alternative specification. I find mixed evidence on the effect of the direct certification systems on free lunch enrollment. In the difference-in-difference specification (Panel A), I find that the effect of the SNAP expansion on participation in SNAP (column 1) and free/reduced-price lunch (columns 2 and 3) is not different between high and low DC states. However, the results in triple difference specification (Panel B) show that high DC states experience a larger increase in free lunch enrollment than low DC states (column 2), even though the impacts on enrollment in SNAP are similar for high and low DC states (column 1).

\section{3) Program Awareness}

An informational intervention to improve take-up among eligible individuals may be more effective when it targets populations that are unaware of assistance programs, but willing to participate in such programs. An interesting feature of the recent SNAP expansion is that households that are eligible through $\mathrm{BBCE}$ receive a brochure or contact information on other state-level assistance programs in the application process. A majority of BBCE states provide a brochure on assistance programs such as

\footnotetext{
${ }^{24}$ I also estimate the effect of application costs using the fraction of LEAs using DC (ranging from 0 to 1 ) instead of the indicator for the high DC state. Results are similar, though estimated with less precision.

${ }^{25}$ The corresponding triple difference specification for this analysis is:$$
Y_{i s t}=\alpha+\beta_{1} L_{O W I N C} \cdot \text { HIGHDC }_{s t} \cdot \text { SIMELIG }_{s t}+\beta_{2} \text { LOWINC }_{i t} \cdot \operatorname{SIMELIG}_{s t}+\beta_{3} \text { LOWINC }_{i t} \cdot \mathrm{HIGHDC}_{s t}
$$$$
+\beta_{4} H_{I G H D C_{i t}} \cdot \text { SIMELIG }_{s t}+\beta_{5} \text { HIGHDC }_{s t}+\beta_{6} \text { LOWINC }_{i t}+\beta_{7} \text { SIMELIG }_{s t}+\operatorname{LOWINC}_{i t} \cdot \theta_{s}
$$$$
+\operatorname{LOWINC}_{i t} \cdot \mu_{t}+\sigma \operatorname{LOWINC}_{i t} \cdot Z_{s t}+\theta_{s}+\mu_{t}+\gamma X_{i s t}+\delta Z_{s t}+\varepsilon_{i s t}
$$ 
Medicaid and TANF while other states use referral to services on the application form or approval letters. Furthermore, there is variation in programs referenced in the brochure and applications. For example, the brochure that SNAP households receive in Connecticut contains information on a broad range of programs including Medicaid, WIC, the school lunch program, and public housing, whereas Minnesota provides qualified SNAP applicants with a brochure only about domestic violence (see Appendix Figure 2 for sample brochures).

I take advantage of variation in the program information provided to SNAP applicants to test the role of program awareness on program spillovers. Specifically, I first exclude 5 states for which I was unable to obtain the $\mathrm{BBCE}$ brochure or referral information. Using the remaining states, I construct two dummy variables: "info. on WIC" indicating if a state provides a brochure or referral information on WIC to SNAP applicants and "info. on NSLP" indicating if a state provides a brochure or referral information on the school lunch program. For some states, SNAP application forms contain information regarding WIC or the school lunch program regardless of their BBCE status. I also take this information into account when constructing the variables for "info. on WIC" and "info. on NSLP". ${ }^{26}$

$<$ Table 8 here>

The specification in Table 8 includes the "info. on WIC" indicator and its interaction with simulated eligibility. The coefficients on the interaction term measure the impact of the SNAP expansion on outcomes for states that provide information on WIC program relative to those that do not. The results in Table 8 indicate that the effect of SNAP expansions on SNAP and WIC enrollment do not differ between states providing WIC information and those that do not. Therefore, the increased WIC enrollment is not driven by heighted awareness of the existence of the program during the SNAP application process as measured by variations in information through brochures.

<Table 9 here>

\footnotetext{
${ }^{26}$ When a state provides only a website address for services, I consider the state as not providing information on WIC or the school lunch program. Although I could not collect brochure/referral information in every year, I confirm that the programs in the brochure or referral information have changed little since the states implemented BBCE by contacting a number of state offices.
} 
Table 9 performs a similar exercise, but focuses on the effect of information on the school lunch program on free/reduced-price lunch enrollment. The results in column 1 show that states that provide information on the NSLP during the SNAP application process see a greater increase in SNAP enrollment due to the SNAP expansion as compared to those that do not, though the estimates are not precise. Despite a larger increase in SNAP enrollment, states providing NSLP information do not experience a larger increase in free school lunch or reduced-price lunch participation than those that do not (columns 2 and 3). Turning to the triple difference specification (Panel B), I find evidence that states that provide information on the NSLP see a significantly larger increase in free school lunch enrollment than those that do not (column 2). However, the fact that these states also experience a larger increase in SNAP participation (column 1) makes it difficult to conclude the causal role of program information.

In sum, the analysis in Tables 8 and 9 points to the conclusion that the provision of program information does not play a role in the spillover effects to WIC and free school lunch participation. This finding raises the possibility that SNAP applicants were aware of both WIC and the school lunch program before they applied for SNAP. The little impact of providing program information may also reflect that the current brochure SNAP participants receive does not have enough information about the program rules or enrollment process. It is important to note, however, that people may learn about other safety net programs through other sources such as communication with caseworkers, and my analysis is silent on whether other types of information improve program take-up.

\section{Conclusion}

Understanding the way SNAP interacts with other health and nutrition programs is the key to assessing the efficacy of SNAP in achieving its stated goals. Despite this fact, previous literature on SNAP focuses on its direct effect in isolation from other safety net programs. This paper provides novel evidence on the relationship between SNAP and participation in health and other nutrition programs. Exploiting a recent and large variation in SNAP eligibility across state and over time, I find evidence that expanded eligibility for SNAP not only increases SNAP participation but also increases free school lunch 
enrollment. More surprisingly, SNAP expansions lead to a reduction in private insurance coverage for both adults and children, which is not fully explained by an increase in Medicaid enrollment.

I also explore which mechanisms underlie the program interactions. I find that bundled eligibility and a reduction in employment, which is concentrated among married-couple households, are responsible for the effects of the SNAP expansions on participation in other programs. I also find suggestive evidence that a reduction in application costs through direct certification systems increases free lunch enrollment, whereas I find no evidence that providing program information affects take-up.

These findings shed light on the importance of quantifying program interactions in order to develop a policy which achieves broad goals of the safety net programs as a whole. While receiving free school lunch is likely to reinforce the positive nutrition effect from SNAP receipt, the costs of the SNAP expansion are also amplified by the spillover effect. More importantly, my findings suggest that lowincome households with children face larger work disincentives because of the program interactions. This reduced work effort, combined with a reduction in health insurance coverage, may offset the positive nutrition effects from SNAP and free lunch benefits. It is important to emphasize that, however, the eligibility expansion occurred during the recession and it targeted a particular income group, which accounts for a small fraction of total SNAP recipients. Therefore, one has to be cautious to extrapolate the results of this study to other income groups or the current labor market.

My findings also provide insight into designing policies that efficiently deliver resources to those in need. My results show that bundling program eligibility and automatic enrollment are effective policy levers to encourage free school lunch take-up. This finding is consistent with recent papers (Edwards et al, 2013; Wilkinson et al, 2014, Hoag, 2015) that document an increase in Medicaid participation as a result of the Express Lane Eligibility (ELE) policy: automation in the enrollment and renewal process for Medicaid by using data from other agencies such as SNAP and TANF. By contrast, I find that lack of program awareness is not the main factor deterring take-up of WIC and the school lunch benefits. To ensure that the brochure conveys relevant information to SNAP participants, states may consider 
providing detailed information on programs of which SNAP households are less aware, instead of simply listing a number of assistance programs with a short description. 


\section{References}

Aizer, Anna. "Public Health Insurance, Program Take-Up, and Child Health." The Review of Economics and Statistics, 2007: 89(3): 400-415.

Baicker, Katherine, Amy Finkelstein, Jae Song, and Sarah Taubman. "The Impact of Medicaid on Labor Market Activity and Program Participation: Evidence from the Oregon Health Insurance Experiment." American Economic Review P\&P, 2014: 322-328.

Bartfeld, Judith. "SNAP and the School Meal Programs." In SNAP Matters: How Food Stamps Affect Health and Well Being, by J. Bartfeld, C. Gundersen, T. Smeeding and J. Ziliak. (eds.), Redwood City, CA: Stanford University Press, 2015.

Bertrand, Marianne, Sendhil Mullainathan, and Eldar Shafir. "Behavioral Economics and Marketing in Aid of Decision Making among the Poor." Journal of Public Policy and Marketing, 2006: 25(1): 8-23.

Bertrand, Marianne, Sendhil Mullainathan, and Erzo Luttmer. "Network Effects and Welfare Cultures." Quarterly Journal of Economics, 2000: 115(3): 1019-1055.

Bhargava, Saurabh, and Dayanand Manoli. "Psychological Frictions and the Incomplete Take-Up of Social Benefits: Evidence from an IRS Field Experiment." American Economic Review, 2015: 105(11): 34893529.

Bitler, Marianne P., Janet Currie, and John Karl Scholz. "WIC Eligibility and Participation." Journal of Human Resources, 2003: 38(S): 1139-1179.

Blank, Rebecca M., and Patricia Ruggles. "When Do Women Use Aid to Families with Dependent Children and Food Stamps? The Dynamics of Eligibility Versus Participation." Journal of Human

Resources, 1996: 31(1): 57-89.

Chetty, Raj, John N. Friedman, and Emmanuel Saez. "Using Differences in Knowledge across Neighborhoods to Uncover the Impacts of the EITC on Earnings." American Economic Review, 2013: 103(7): 2683-2721.

Clemens, Jeffrey. "Redistribution through Minimum Wage Regulation: An Analysis of Program Linkages and Budgetary Spillovers." Tax Policy and the Economy, 2016: 30: 163-189.

Currie, Janet M. "The Take-up of Social Benefits." In Poverty, the Distribution of Income, and Public Policy, by Alan Auerbach, David Card and John Quigley (eds), 80-148. New York: Russell Sage, 2006.

Currie, Janet, and Jeffrey Grogger. "Explaining Recent Declines in Food Stamp Program Participation." Brookings-Wharton Papers on Urban Affairs, 2001: 203-244.

Cutler, D. and Gruber, J. "Does public health insurance crowd-out private insurance?" Quarterly Journal of Economics, 1996: 111(2): 391-430.

Dahl, Gordon B., Katrine Løken, and Magne Mogstad. "Peer Effects in Program Participation." American Economic Review, 2014: 104(7): 2049-2074.

Daponte, Beth Osborne, Seth Sanders, and Lowell Taylor. "Why Do Low-Income Households not Use Food Stamps? Evidence from an Experiment." The Journal of Human Resources, 1999: 34(3): 612-628.

Decker, Sandra L., and Frederic W. Selck. "The effect of the original introduction of Medicaid on welfare participation and female labor supply." Review of Economics of the Household, 2012: 10(4): 541-556. Duflo, Esther, and Emmanuel Saez. "The Role of Information and Social Interactions in Retirement Plan Decisions: Evidence from a Randomized Experiment." Quarterly Journal of Economics, 2003: 118 (3): 815-42. 
Ebenstein, Avraham, and Kevin Stange. "Does Inconvenience Explain Low Take-up? Evidence from Unemployment Insurance." Journal of Policy Analysis and Management, 2010: 29(1): 111-36.

Edelstein, Sara, Michael R. Pergamit, and Caroline Ratcliffe. "Characteristics of Families Receiving Multiple Public Benefits." Washington, DC: The Urban Institute, 2014.

Edwards, Jennifer, and Rebecca Kellenberg. "Case Study of South Carolina's Express Lane Eligibility." Mathematica Policy Research, 2013.

Fraker, Thomas, and Robert Moffitt. "The effect of food stamps on labor supply: A bivariate selection model." Journal of Public Economics, 1988: 35(1): 25-56.

Ganong, Peter, and Jeffrey B. Liebman. "The decline, rebound, and further rise in snap enrollment: Disentangling business cycle fluctuations and policy changes." Working paper, 2015.

Gothro, Andrew, and Carole Trippe. "Multiple Benefit Receipt Among Individuals Receiving Food Assistance and Other Government Assistance." Mathematica Policy Research , 2010.

Hagstrom, Paul A. "The Food Stamp Participation and Labor Supply of Married Couples: An Empirical Analysis." Journal of Human Resources, 1996: 31(2): 383-403.

Ham, John C., and Lara D. Shore-Sheppard. "Did expanding Medicaid affect welfare participation?" Industrial and Labor Relations Review, 2005: 58(3): 452-470.

Hanratty, Maria J. "Has the Food Stamp program become more accessible? Impacts of recent changes in reporting requirements and asset eligibility limits." Journal of Policy Analysis and Management, 2006: 25(3): 603-621.

Hastings, Justine S., and Lydia Tejeda-Ashton. "Financial Literacy, Information, and Demand Elasticity: Survey and Experimental Evidence from Mexico." Working paper, 2008.

Hoag, Sheila D. "Spotlight on Express Lane Eligibility (ELE): A Tool to Improve Enrollment and Renewal." Academic Pediatrics, 2015: 15(3): S28-S35.

Hoynes, H. and Schanzenbach, D.W. "Work incentives and the Food Stamp Program." Journal of Pulbic Economics, 2012: 96(1): 151-162.

Hoynes, Hilary W., and Diane Whitmore Schanzenbach. "U.S. Food and Nutrition Programs." MeansTested Transfer Programs In the United States, 2015: Volume II.

Jones, Damon. "Information, Preferences, and Public Benefit Participation: Experimental Evidence from the Advance EITC and 401(k) Savings." American Economic Journal: Applied Economics, 2010: 2(2): 14763.

Keane, Michael, and Robert Moffitt. "A Structural Model of Multiple Welfare Program Participation and Labor Supply." International Economic Review, 1998: 39(3): 553-89.

Kling, Jeffrey R., Sendhil Mullainathan, Eldar Shafir, Lee Vermeulen, and Marian Wrobel. "Comparison Friction: Experimental Evidence from Medicare Drug Plans." Quarterly Journal of Economics, 2012: 127(1): 199-235.

Koch, Thomas G. "All Internal in the Family? Measuring Spillovers from Public Health Insurance." Journal of Human Resources, 2015: 50(4): 959-979.

Laird, Elizabeth, and Carole Trippe. "Programs Conferring Categorical Eligibility for SNAP: State Policies and the Number and Characteristics of Households Affected." Mathematica Policy Research, 2014. Lindner, Stephan, and Austin Nichols. "The Impact of Temporary Assistance Programs on Disability Rolls and Re-Employment." CRR Working Paper 2012-2, 2012. 
Marton, James, and Aaron Yelowitz. "Health Insurance Generosity and Conditional Coverage: Evidence from medicaid managed care in Kentucky." Southern Economic Journal, 2015: 82(2): 535-555.

Moffitt, Robert A. "Multiple Program Participation and the SNAP Program." In SNAP Matters: How Food Stamps Affect Health and Well Being, by J. Bartfeld, C. Gundersen, T. Smeeding and J. Ziliak. (eds.), Redwood City, CA: Stanford University Press, 2015.

Mulligan, Casey B. "The Redistribution Recession: How Labor Market Distortions Contracted the Economy." Oxford University Press, 2012.

Olds, Gareth. "Food Stamp Entrepreneurs." Harvard Business School Working Paper, 2016: No. 16-143.

Oliveira, Victor, and Elizabeth Frazao. The WIC Program: Background, Trends, and Economic Issues, 2015 Edition. EIB-134, U.S. Department of Agriculture, Economic Research Service, January 2015.

Trippe, Carole, and Jessica Gillooly. "Non-Cash Categorical Eligibility For SNAP: State Policies and the Number and Characteristics of SNAP Households Categorically Eligilble Through Those Policies."

Mathematica Policy Research, 2010.

Wilkinson, Margaret, Brigette Courtot, and Ian Hill. "Case Study of Alabama's Express Express Lane Eligibility." Mathematica Policy Research, 2014.

Yelowitz, Aaron S. "Did Recent Medicaid Reforms Cause the Caseload Explosion in the Food Stamp Program?" Working Paper, 1996.

Yelowitz, Aaron S. "The Medicaid Notch, Labor Supply and Welfare Participation: Evidence From Eligibility Expansions." Quarterly Journal of Economics, 1995: 110(4): 909-939.

Yelowitz, Aaron S. "Using the Medicare Buy-In Program to Estimate the Effect of Medicaid on the SSI Participation." Economic Inquiry, 2000: 38(3): 419-441.

Ziliak, James P. "Why Are So Many Americans on Food Stamps? The Role of the Economy, Policy, and Demographics." In SNAP Matters: How Food Stamps Affect Health and Well Being, by J. Bartfeld, C. Gundersen, T. Smeeding and J. Ziliak. (eds.), Redwood City, CA: Stanford University Press, 2015. 
Figure 1. Labor supply response to the SNAP eligibility expansion

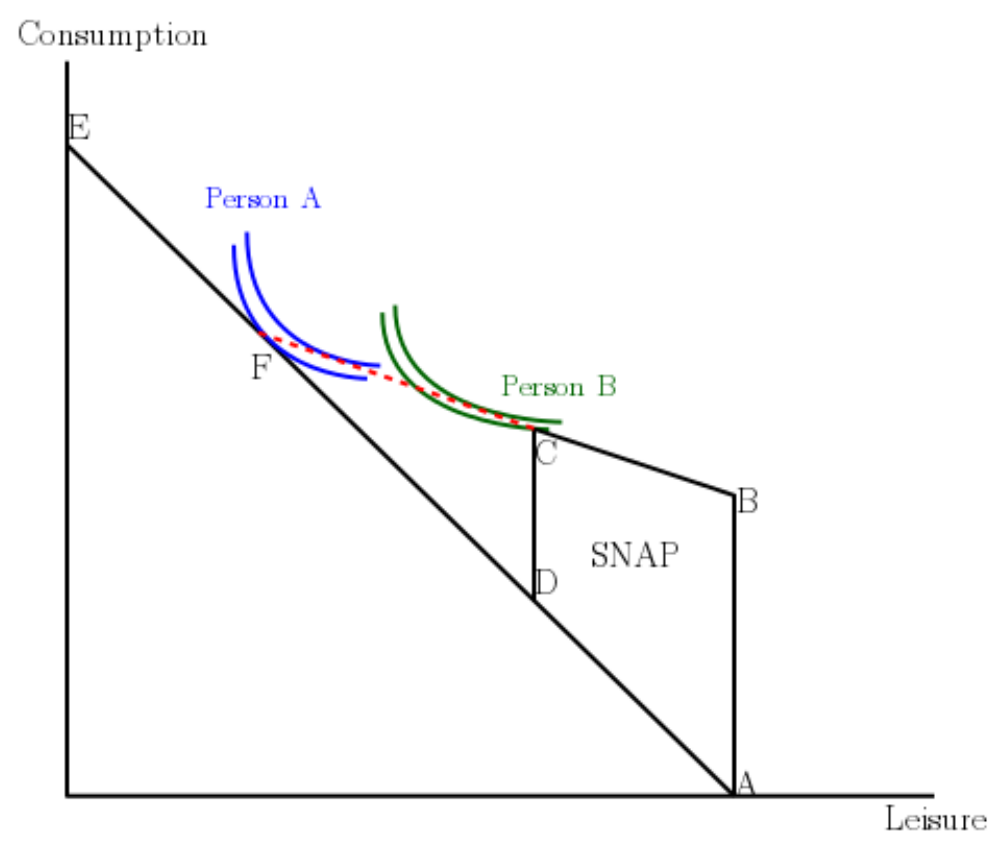


Figure 2. Trends in simulated eligibility and SNAP enrollment
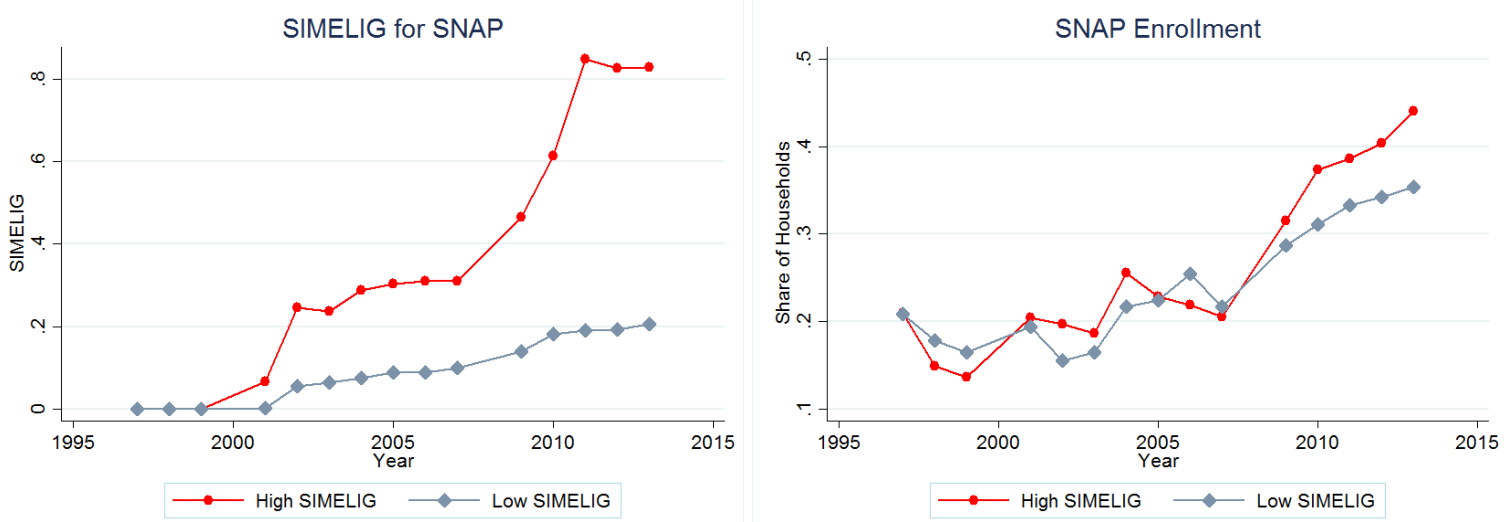

Notes: This figure presents trends in simulated eligibility and the actual SNAP enrollment among households with children and gross annual income 100\%-200\% FPL using the SIPP 1997-2013. I partition states into two groups based on the level of simulated eligibility: "High simulated eligibility" states have simulated eligibility greater than or equal to 0.5 by 2013 and "Low simulated eligibility" states have simulated eligibility smaller than 0.5 over the entire period from 1997-2013. 23 states and D.C. are high simulated eligibility states while the remaining 27 states are low simulated eligibility states. Estimates are weighted using the household weights. 
Table 1. Summary Statistics

Gross Income Gross Income

100\%-200\% FPL 200\%-300\% FPL

Participation in Nutrition Programs

SNA

WIC*

0.251

0.070

Free school lunch**

0.491

0.234

0.568

0.235

Reduced-price Lunch**

0.213

0.154

Health Insurance Coverage

Any Insurance

0.949

0.974

Private Insurance

0.746

0.926

Medicaid

0.573

0.296

Demographics

Female headed household

$0.580 \quad 0.504$

Has self employed member

0.154

0.177

Has African-American member

0.205

0.149

Has Hispanic member

0.308

0.204

Household size

4.107

4.019

Age of adults ( $>=18$ )

37.36

38.04

Has married member

0.669

0.771

Live in urban area

0.769

0.781

Renter

0.426

0.261

Has member with H.S Degree or above

0.869

0.956

Has member with College or above

0.363

0.513

Has disabled member

0.017

0.022

Has elderly (age $>=60$ ) member

0.090

0.086

Has a child under age 5

0.366

0.334

Has a child aged 5-17

0.827

0.806

Number of children

2.010

1.809

$\mathrm{N}$

22,710

21,619

Notes: Data are from SIPP 1997-2013. This table presents the mean of all outcomes and demographic variables for households with children and gross annual income $100 \%$ $200 \% \mathrm{FPL}$ (column 1) and households with children and gross annual income $200 \%$ $300 \%$ FPL (column 2). All dollar amounts are in 2010 dollars. Statistics are weighted using the household weights. ${ }^{*}$ The sample is restricted to households with children aged $0-4$ and $\mathrm{N}=9,201(8,671)$ for the sample in column 1 (column 2 ). ${ }^{* *}$ The sample is restricted to households with children aged $5-17$ and $N=18,859(17,668)$ for the sample in column 1 (column 2). 
Table 2. Effect of State Economic Conditions on State SNAP Eligibility Expansion

\begin{tabular}{|c|c|c|c|c|}
\hline \multirow{2}{*}{$\begin{array}{l}\text { Time Period } \\
\text { Dependent Variable }\end{array}$} & \multicolumn{2}{|c|}{ Years 2000-2013 } & \multicolumn{2}{|c|}{ Years 2007-2013 } \\
\hline & $\operatorname{BBCE}(1 / 0)$ & SIMELIG & $\operatorname{BBCE}(1 / 0)$ & SIMELIG \\
\hline \multicolumn{5}{|c|}{ Panel A: Level of the unemployment rate } \\
\hline \multirow[t]{2}{*}{$U R(t)$} & $0.065^{* *}$ & $0.052 * * *$ & 0.050 & 0.036 \\
\hline & $(0.030)$ & $(0.016)$ & $(0.035)$ & $(0.023)$ \\
\hline \multirow[t]{2}{*}{$U R(t-1)$} & 0.017 & 0.002 & 0.032 & 0.001 \\
\hline & $(0.015)$ & $(0.014)$ & $(0.023)$ & $(0.017)$ \\
\hline \multirow[t]{2}{*}{$U R(t-2)$} & -0.016 & 0.026 & 0.004 & $0.047 * *$ \\
\hline & $(0.026)$ & $(0.020)$ & $(0.022)$ & $(0.021)$ \\
\hline R-squared & 0.725 & 0.761 & 0.785 & 0.800 \\
\hline \multicolumn{5}{|c|}{ Panel B: Change in the unemployment rate } \\
\hline \multirow[t]{2}{*}{$U R(t)-U R(t-1)$} & 0.021 & -0.001 & -0.013 & -0.027 \\
\hline & $(0.019)$ & $(0.018)$ & $(0.022)$ & $(0.025)$ \\
\hline \multirow[t]{2}{*}{$U R(t-1)-U R(t-2)$} & $0.056 * * *$ & 0.021 & $0.039 * *$ & -0.005 \\
\hline & $(0.016)$ & $(0.016)$ & $(0.015)$ & $(0.017)$ \\
\hline R-squared & 0.716 & 0.735 & 0.775 & 0.784 \\
\hline Mean of Dep. Var & 0.456 & 0.268 & 0.697 & 0.408 \\
\hline S.D. of Dep. Var & 0.498 & 0.342 & 0.460 & 0.354 \\
\hline Mean of UR & \multicolumn{2}{|c|}{6.0} & \multicolumn{2}{|c|}{7.1} \\
\hline S.D. of UR & \multicolumn{2}{|c|}{2.1} & \multicolumn{2}{|c|}{2.2} \\
\hline$N$ & \multicolumn{2}{|c|}{686} & \multicolumn{2}{|c|}{343} \\
\hline
\end{tabular}

Notes: This table reports estimates from OLS regressions of a state SNAP policy parameter (BBCE status or level of simulated eligibility) on measures for state labor market conditions, which are defined either using the state unemployment rates (Panel A), or using changes in state unemployment rates (Panel B). Columns 1-2 use years from 2000-2013, while columns 34 use years from 2007-2013. All specifications include year FE, state FE, and the political condition measures such as the fraction of State House/Senate that is Democrat and an indicator for whether the governor of the state is Democrat. D.C. and Nebraska are excluded from the analysis. BBCE is an indicator for having any form of BBCE programs. Simulated eligibility level used is for households with children. SNAP policy data come from the Economic Research Service's SNAP Policy Database and the Mathematica Policy Research's reports. The state unemployment rate comes from the BLS. State politics data come from the University of Kentucky Center for Poverty Research. 
Table 3. The Effect of SNAP Expansions on SNAP Participation

\begin{tabular}{|c|c|c|c|}
\hline \multirow[t]{2}{*}{ Dependent Variable } & \multicolumn{3}{|c|}{ SNAP } \\
\hline & $\begin{array}{c}\text { All HHs } \\
\text { with children }\end{array}$ & $\begin{array}{c}\text { WIC } \\
\text { Eligible HHs }\end{array}$ & $\begin{array}{c}\text { School } \\
\text { Lunch } \\
\text { Eligible HHs }\end{array}$ \\
\hline \multicolumn{4}{|l|}{ Panel A. DD } \\
\hline \multirow[t]{2}{*}{ Simulated Eligibility } & $0.060 * *$ & $0.082 * *$ & $0.068 * *$ \\
\hline & $(0.024)$ & $(0.031)$ & $(0.027)$ \\
\hline Mean of Dep. Var & 0.2510 & 0.2772 & 0.2457 \\
\hline $\mathrm{N}$ & 22,710 & 9,697 & 19,970 \\
\hline \multicolumn{4}{|l|}{ Panel B. DDD } \\
\hline \multirow[t]{2}{*}{ Simulated Eligibility*[100-200\% FPL] } & $0.066 * * *$ & 0.056 & $0.076 * * *$ \\
\hline & $(0.022)$ & $(0.034)$ & $(0.027)$ \\
\hline Mean of Dep. Var & 0.1619 & 0.1894 & 0.1581 \\
\hline $\mathrm{N}$ & 44,329 & 17,987 & 38,698 \\
\hline \multicolumn{4}{|c|}{$\begin{array}{l}\text { Notes: Data are from SIPP 1997-2013. Panel A reports estimates from equation (2) on samples of } \\
\text { households with children and gross annual income } 100 \%-200 \% \text { FPL. Panel B reports estimates from } \\
\text { equation (4) on samples of households with children and gross annual income } 100 \%-300 \% \text { FPL. In column } 2 \text {, } \\
\text { the samples are restricted to households with children under age } 5 \text {. In column } 3 \text {, the samples are restricted } \\
\text { to households with children aged 5-17. All specifications include demographic controls listed in Table } 1 \text {, } \\
\text { imputed Medicaid/CHIP eligibility, year FE, state FE, and state characteristics such as the state } \\
\text { unemployment rates, } 1 \text { and 2-year lags in the state unemployment rates, the state poverty rates, minimum } \\
\text { wage, TANF maximum benefit levels, EITC parameters, and other changes in SNAP beside BBCE listed in } \\
\text { footnote } 11 \text {. All dollar amounts are in } 2010 \text { dollars. Estimates are weighted using the household weights } \\
\text { and robust standard errors clustered at the state level in parentheses. } * * * 0.01, * * 0.05, * 0.1 \text {. }\end{array}$} \\
\hline
\end{tabular}


Table 4. The Effect of SNAP Expansions on Other Nutrition Program Participation

\begin{tabular}{|c|c|c|c|}
\hline Dependent Variable & WIC & $\begin{array}{l}\text { Free School } \\
\text { Lunch }\end{array}$ & $\begin{array}{l}\text { RP School } \\
\text { Lunch }\end{array}$ \\
\hline \multicolumn{4}{|l|}{ Panel A. DD } \\
\hline \multirow[t]{2}{*}{ Simulated Eligibility } & $0.096 * *$ & $0.040^{*}$ & -0.015 \\
\hline & $(0.043)$ & $(0.020)$ & $(0.022)$ \\
\hline Mean of Dep. Var & 0.4907 & 0.5684 & 0.2128 \\
\hline $\mathrm{N}$ & 9,697 & 19,970 & 19,970 \\
\hline \multicolumn{4}{|l|}{ Panel B. DDD } \\
\hline \multirow[t]{2}{*}{ Simulated Eligibility*[100-200\% FPL] } & 0.093 & $0.084 * * *$ & 0.035 \\
\hline & $(0.063)$ & $(0.024)$ & $(0.026)$ \\
\hline Mean of Dep. Var & 0.3700 & 0.4058 & 0.1839 \\
\hline $\mathrm{N}$ & 18,097 & 38,698 & 38,698 \\
\hline \multicolumn{4}{|c|}{$\begin{array}{l}\text { Notes: Data are from SIPP 1997-2013. Panel A reports estimates from equation (2) on samples of } \\
\text { households with children and gross annual income } 100 \%-200 \% \text { FPL. Panel B reports estimates from } \\
\text { equation (4) on samples of households with children and gross annual income } 100 \%-300 \% \text { FPL. In column } 1 \text {, } \\
\text { the samples consist of households with children under age } 5 \text {. In columns } 2 \text { and } 3, \text { the samples consist of } \\
\text { households with children aged 5-17. All specifications include demographic controls listed in Table } 1 \text {, } \\
\text { imputed Medicaid/CHIP eligibility, year FE, state FE, and state characteristics such as the state } \\
\text { unemployment rates, } 1 \text { and 2-year lags in the state unemployment rates, the state poverty rates, minimum } \\
\text { wage, TANF maximum benefit levels, EITC parameters, and other changes in SNAP beside BBCE listed in } \\
\text { footnote } 11 \text {. All dollar amounts are in } 2010 \text { dollars. Estimates are weighted using the household weights } \\
\text { and robust standard errors clustered at the state level in parentheses. }{ }^{* * *} 0.01,{ }^{* *} 0.05,{ }^{*} 0.1 \text {. }\end{array}$} \\
\hline
\end{tabular}


Table 5. The Effect of SNAP Expansions on Health Insurance Coverage

\begin{tabular}{|c|c|c|c|c|c|c|}
\hline Dependent Variable & $\begin{array}{l}\text { Any Adults } \\
\text { Any Ins. }\end{array}$ & $\begin{array}{l}\text { Any Adults } \\
\text { Private Ins. }\end{array}$ & $\begin{array}{l}\text { Any Adults } \\
\text { Medicaid }\end{array}$ & $\begin{array}{l}\text { Any Children } \\
\text { Any Ins. }\end{array}$ & $\begin{array}{l}\text { Any Children } \\
\text { Private Ins. }\end{array}$ & $\begin{array}{c}\text { Any } \\
\text { Children } \\
\text { Medicaid } \\
\end{array}$ \\
\hline \multicolumn{7}{|l|}{ Panel A. DD } \\
\hline \multirow[t]{2}{*}{ Simulated Eligibility } & $-0.038 * *$ & $-0.074 * * *$ & 0.001 & -0.019 & $-0.060 * *$ & 0.022 \\
\hline & $(0.015)$ & $(0.019)$ & $(0.028)$ & $(0.018)$ & $(0.024)$ & $(0.033)$ \\
\hline Mean of Dep. Var & 0.8680 & 0.7007 & 0.3501 & 0.9041 & 0.5726 & 0.5354 \\
\hline \multicolumn{7}{|l|}{ Panel B. DDD } \\
\hline \multirow[t]{2}{*}{ Simulated Eligibility*[100-200\% FPL] } & -0.034 & $-0.081 * * *$ & -0.008 & -0.020 & $-0.075^{* *}$ & 0.046 \\
\hline & $(0.021)$ & $(0.028)$ & $(0.036)$ & $(0.022)$ & $(0.029)$ & $(0.040)$ \\
\hline Mean of Dep. Var & 0.9065 & 0.8053 & 0.2576 & 0.9214 & 0.6914 & 0.3994 \\
\hline \multicolumn{7}{|l|}{ Panel C. DD, Lagged SIMELIG } \\
\hline \multirow[t]{2}{*}{ Simulated Eligibility(t-1) } & -0.021 & $-0.072 * * *$ & 0.026 & -0.014 & $-0.063^{* *}$ & 0.027 \\
\hline & $(0.015)$ & $(0.024)$ & $(0.023)$ & $(0.020)$ & $(0.027)$ & $(0.031)$ \\
\hline Mean of Dep. Var & 0.8680 & 0.7007 & 0.3501 & 0.9041 & 0.5726 & 0.5354 \\
\hline \multicolumn{7}{|l|}{ Panel D. DDD, Lagged SIMELIG } \\
\hline \multirow[t]{2}{*}{ Simulated Eligibility(t-1)*[100-200\% FPL] } & -0.028 & $-0.092 * * *$ & 0.034 & -0.014 & $-0.086 * *$ & 0.061 \\
\hline & $(0.020)$ & $(0.032)$ & $(0.034)$ & $(0.021)$ & $(0.035)$ & $(0.037)$ \\
\hline Mean of Dep. Var & 0.9065 & 0.8053 & 0.2576 & 0.9214 & 0.6914 & 0.3994 \\
\hline $\mathrm{N}$ (Panels $\mathrm{A}$ and $\mathrm{C})$ & \multicolumn{6}{|c|}{22,710} \\
\hline N (Panels B and D) & \multicolumn{6}{|c|}{44,329} \\
\hline \multicolumn{7}{|c|}{$\begin{array}{l}\text { Notes: Data are from SIPP 1997-2013. Panel A reports estimates from equation (2) on samples of households with children and gross annual income } 100 \% \text { - } \\
200 \% \text { FPL. Panel B reports estimates from equation (4) on samples of households with children and gross annual income } 100 \%-300 \% \text { FPL. Panel C reports } \\
\text { estimates from a version of equation (2) where simulated eligibility is replaced with 1-year lagged simulated eligibility. Panel D reports estimates from a } \\
\text { version of equation (4) where simulated eligibility is replaced with 1-year lagged simulated eligibility. All specifications include demographic controls listed } \\
\text { in Table } 1 \text {, imputed Medicaid/CHIP eligibility, year FE, state FE, and state characteristics such as the state unemployment rates, } 1 \text { and } 2 \text {-year lags in the } \\
\text { state unemployment rates, the state poverty rates, minimum wage, TANF maximum benefit levels, EITC parameters, and other changes in SNAP beside } \\
\text { BBCE listed in footnote } 11 \text {. All dollar amounts are in } 2010 \text { dollars. Estimates are weighted using the household weights and robust standard errors clustered } \\
\text { at the state level in parentheses. }{ }^{* * * 0.01, * * 0.05, * 0.1 .}\end{array}$} \\
\hline
\end{tabular}


Table 6. The Effect of SNAP Expansions on Labor Supply

\begin{tabular}{|c|c|c|c|c|}
\hline Dependent Variable & $\begin{array}{c}\text { Head } \\
\text { Employed }\end{array}$ & Head Hours & $\begin{array}{l}\text { Head Hours } \\
\text { if Emp. }\end{array}$ & $\begin{array}{c}\text { Head } \\
\text { Earnings }\end{array}$ \\
\hline \multicolumn{5}{|l|}{ Panel A. DD, all households with children } \\
\hline \multirow[t]{2}{*}{ Simulated Eligibility } & -0.022 & -0.139 & 0.768 & $-89.030 *$ \\
\hline & $(0.020)$ & $(0.764)$ & $(0.711)$ & $(49.869)$ \\
\hline \multirow[t]{2}{*}{ Mean of Dep. Var } & 0.79 & 29.79 & 37.55 & 1348.0 \\
\hline & 22,710 & 22,710 & 17,649 & 22,710 \\
\hline \multicolumn{5}{|l|}{ Panel B. DDD, all households with children } \\
\hline \multirow[t]{2}{*}{ Simulated Eligibility*[100-200\% FPL] } & $-0.050 *$ & -1.834 & 0.047 & -120.933 \\
\hline & $(0.025)$ & $(1.212)$ & $(0.798)$ & $(77.641)$ \\
\hline \multirow[t]{2}{*}{ Mean of Dep. Var } & 0.83 & 32.40 & 38.83 & 1786.0 \\
\hline & 44,329 & 44,329 & 36,373 & 44,329 \\
\hline \multicolumn{5}{|l|}{ Panel C. DD, two-parent households } \\
\hline \multirow[t]{2}{*}{ Simulated Eligibility } & -0.043 & -0.702 & 0.613 & $-109.716^{*}$ \\
\hline & $(0.026)$ & $(0.933)$ & $(0.913)$ & $(56.016)$ \\
\hline \multirow[t]{2}{*}{ Mean of Dep. Var } & 0.77 & 29.43 & 37.98 & 1361.56 \\
\hline & 14,320 & 14,320 & 10,973 & 14,320 \\
\hline \multicolumn{5}{|l|}{ Panel D. DDD, two-parent households } \\
\hline \multirow[t]{2}{*}{ Simulated Eligibility*[100-200\% FPL] } & $-0.073 * *$ & $-3.089 * *$ & -0.804 & 204.809** \\
\hline & $(0.034)$ & $(1.423)$ & $(0.989)$ & $(76.437)$ \\
\hline \multirow[t]{2}{*}{ Mean of Dep. Var } & 0.82 & 32.21 & 39.10 & 1812.0 \\
\hline & 30,398 & 30,398 & 24,836 & 30,398 \\
\hline \multicolumn{5}{|l|}{ Panel E. DD, single-parent households } \\
\hline \multirow[t]{2}{*}{ Simulated Eligibility } & 0.004 & 0.336 & 0.373 & -76.537 \\
\hline & $(0.023)$ & $(1.038)$ & $(0.828)$ & $(65.910)$ \\
\hline \multirow[t]{2}{*}{ Mean of Dep. Var } & 0.83 & 30.43 & 36.82 & 1323.9 \\
\hline & 8,390 & 8,390 & 6,676 & 8,390 \\
\hline \multicolumn{5}{|l|}{ Panel F. DDD, single-parent households } \\
\hline \multirow[t]{2}{*}{ Simulated Eligibility*[100-200\% FPL] } & -0.020 & 1.159 & $2.153^{*}$ & 19.824 \\
\hline & $(0.034)$ & $(1.599)$ & $(1.274)$ & $(113.671)$ \\
\hline \multirow[t]{2}{*}{ Mean of Dep. Var } & 0.86 & 32.81 & 38.26 & 1727.2 \\
\hline & 13,931 & 13,931 & 11,537 & 13,931 \\
\hline \multicolumn{5}{|c|}{$\begin{array}{l}\text { Notes: Data are from SIPP 1997-2013. Panel A reports estimates from equation (2) on samples of households with children } \\
\text { and gross annual income } 100 \%-200 \% \text { FPL. Panel B reports estimates from equation (4) on samples of households with } \\
\text { children and gross annual income } 100 \%-300 \% \text { FPL. Panels C and E report estimates from equation (2) on subsamples of } \\
\text { two-parent households and single-parent households, respectively. Panels D and F report estimates from equation (4) on } \\
\text { subsamples of two-parent households and single-parent households, respectively. All specifications include demographic } \\
\text { controls listed in Table } 1 \text {, imputed Medicaid/CHIP eligibility, year FE, state FE, and state characteristics such as the state } \\
\text { unemployment rates, } 1 \text { and 2-year lags in the state unemployment rates, the state poverty rates, minimum wage, TANF } \\
\text { maximum benefit levels, EITC parameters, and other changes in SNAP beside BBCE listed in footnote } 11 \text {. All dollar amounts } \\
\text { are in } 2010 \text { dollars. Estimates are weighted using the household weights and robust standard errors clustered at the state } \\
\text { level in parentheses. } * * * 0.01, * * 0.05, * 0.1 \text {. }\end{array}$} \\
\hline
\end{tabular}


Table 7. The Effect of "Direct Certification" on School Lunch Participation

\begin{tabular}{lccc}
\hline \hline Dependent Variable & SNAP & $\begin{array}{c}\text { Free School } \\
\text { Lunch }\end{array}$ & $\begin{array}{c}\text { RP School } \\
\text { Lunch }\end{array}$ \\
\hline Panel A. DD & & & \\
Simulated Eligibility*High_DC & 0.010 & 0.017 & 0.004 \\
& $(0.042)$ & $(0.031)$ & $(0.043)$ \\
Simulated Eligibility & $0.105^{* * *}$ & $0.070^{* *}$ & $-0.049^{*}$ \\
& $(0.031)$ & $(0.029)$ & $(0.027)$ \\
Mean of Dep. Var & 0.2893 & 0.6121 & 0.2174 \\
N & 11,525 & 11,525 & 11,525 \\
\hline Panel B. DDD & & & \\
Simulated Eligibility*[100-200\% FPL]*High_DC & 0.028 & $0.086^{*}$ & -0.016 \\
& $(0.059)$ & $(0.043)$ & $(0.059)$ \\
Simulated Eligibility*[100-200\% FPL] & $0.115^{* *}$ & $0.110^{* * *}$ & 0.031 \\
& $(0.043)$ & $(0.036)$ & $(0.040)$ \\
Mean of Dep. Var & 0.1911 & 0.4545 & 0.1981 \\
N & 21,794 & 21,794 & 21,794 \\
\hline
\end{tabular}

Notes: Data are from SIPP 1997-2013. Panel A reports estimates from equation (5) on samples of households with children aged 5-17 and gross annual income 100\%-200\% FPL. Panel B reports estimates from equation (6) in footnote 28 on samples of households with children aged 5-17 and gross annual income 100\%-200\% FPL. "High_DC" indicates if a state has a high fraction of LEAs (>85\%) using direct certification systems. All specifications include demographic controls listed in Table 1, imputed Medicaid/CHIP eligibility, year FE, state FE, and state characteristics such as the state unemployment rates, 1 and 2-year lags in the state unemployment rates, the state poverty rates, minimum wage, TANF maximum benefit levels, EITC parameters, and other changes in SNAP beside BBCE listed in footnote 11. All dollar amounts are in 2010 dollars. Estimates are weighted using the household weights and robust standard errors clustered at the state level in parentheses. ${ }^{* * *} 0.01, * * 0.05, * 0.1$. 
Table 8. The Effect of Providing brochure/referral Information on WIC Participation

\begin{tabular}{lcc}
\hline \hline Dependent Variable & SNAP & WIC \\
\hline Panel A: DD & & \\
Simulated Eligibility*WIC Info. & 0.043 & 0.011 \\
& $(0.045)$ & $(0.055)$ \\
Simulated Eligibility & $0.080^{*}$ & $0.099^{*}$ \\
& $(0.042)$ & $(0.056)$ \\
Mean of Dep. Var & 0.2831 & 0.4969 \\
N & 8,776 & 8,776 \\
\hline Panel B: DDD & & \\
Simulated Eligibility*[100-200\% FPL]*WIC Info. & 0.010 & -0.107 \\
& $(0.036)$ & $(0.069)$ \\
Simulated Eligibility*[100-200\% FPL] & $0.089 * *$ & $0.177 * *$ \\
& $(0.037)$ & $(0.070)$ \\
Mean of Dep. Var & 0.1929 & 0.3742 \\
N & 16,401 & 16,401 \\
\hline
\end{tabular}

Notes: Data are from SIPP 1997-2013. Panel A reports estimates from a version of equation (5) where "High_DC" indicator is replaced with "WIC Info." indicator. Panel B reports estimate from a version of equation (6) where "High_DC" indicator is replaced with "WIC Info." indicator. Samples in Panel A consists of households with children under age 5 and gross annual income $100 \%-200 \%$ FPL. Samples in Panel B consists of households with children under age 5 and gross annual income 100\%-300\% FPL. "WIC Info." indicates if a state provides a brochure or referral information on WIC to SNAP applicants. All specifications include demographic controls listed in Table 1, imputed Medicaid/CHIP eligibility, year FE, state $\mathrm{FE}$, and state characteristics such as the state unemployment rates, 1 and 2-year lags in the state unemployment rates, the state poverty rates, minimum wage, TANF maximum benefit levels, EITC parameters, and other changes in SNAP beside BBCE listed in footnote 11. All dollar amounts are in 2010 dollars. Estimates are weighted using the household weights and robust standard errors clustered at the state level in parentheses. ${ }^{* * *} 0.01, * * 0.05, * 0.1$. 
Table 9. The Effect of Providing brochure/referral Information on NSLP Participation

\begin{tabular}{lccc}
\hline \hline Dependent Variable & SNAP & $\begin{array}{c}\text { Free School } \\
\text { Lunch }\end{array}$ & $\begin{array}{c}\text { RP School } \\
\text { Lunch }\end{array}$ \\
\hline Panel A. DD & & & \\
$\quad$ Simulated Eligibility*NSLP Info. & 0.110 & 0.007 & -0.009 \\
& $(0.069)$ & $(0.044)$ & $(0.034)$ \\
Simulated Eligibility & 0.031 & 0.018 & -0.014 \\
& $(0.035)$ & $(0.025)$ & $(0.031)$ \\
Mean of Dep. Var & 0.2484 & 0.5683 & 0.2119 \\
N & 17,888 & 17,888 & 17,888 \\
\hline Panel B. DDD & & & \\
Simulated Eligibility*[100-200\% FPL]*NSLP Info. & 0.108 & $0.106 *$ & -0.029 \\
& $(0.076)$ & $(0.053)$ & $(0.059)$ \\
Simulated Eligibility*[100-200\% FPL] & 0.030 & 0.025 & 0.019 \\
& $(0.028)$ & $(0.029)$ & $(0.032)$ \\
Mean of Dep. Var & 0.1596 & 0.4046 & 0.1837 \\
N & 34,719 & 34,719 & 34,719 \\
\hline
\end{tabular}

Notes: Data are from SIPP 1997-2013. Panel A reports estimates from a version of equation (5) where "High_DC" indicator is replaced with "NSLP Info." indicator. Panel B reports estimate from a version of equation (6) where "High_DC" indicator is replaced with "NSLP Info." indicator. Samples in Panel A consists of households with children aged 5-17 and gross annual income $100 \%-200 \%$ FPL. Samples in Panel B consists of households with children aged 5-17 and gross annual income 100\%-300\% FPL. "NSLP Info." indicates if a state provides a brochure or referral information on the school lunch program to SNAP applicants. All specifications include demographic controls listed in Table 1, imputed Medicaid/CHIP eligibility, year FE, state $\mathrm{FE}$, and state characteristics such as the state unemployment rates, 1 and 2-year lags in the state unemployment rates, the state poverty rates, minimum wage, TANF maximum benefit levels, EITC parameters, and other changes in SNAP beside BBCE listed in footnote 11. All dollar amounts are in 2010 dollars. Estimates are weighted using the household weights and robust standard errors clustered at the state level in parentheses. ${ }^{* * *} 0.01, * * 0.05, * 0.1$. 
Appendix Figure 1. Labor supply response to the SNAP eligibility expansion in the context of multiple programs

Panel A. Effect of automatic eligibility for free lunch on labor supply

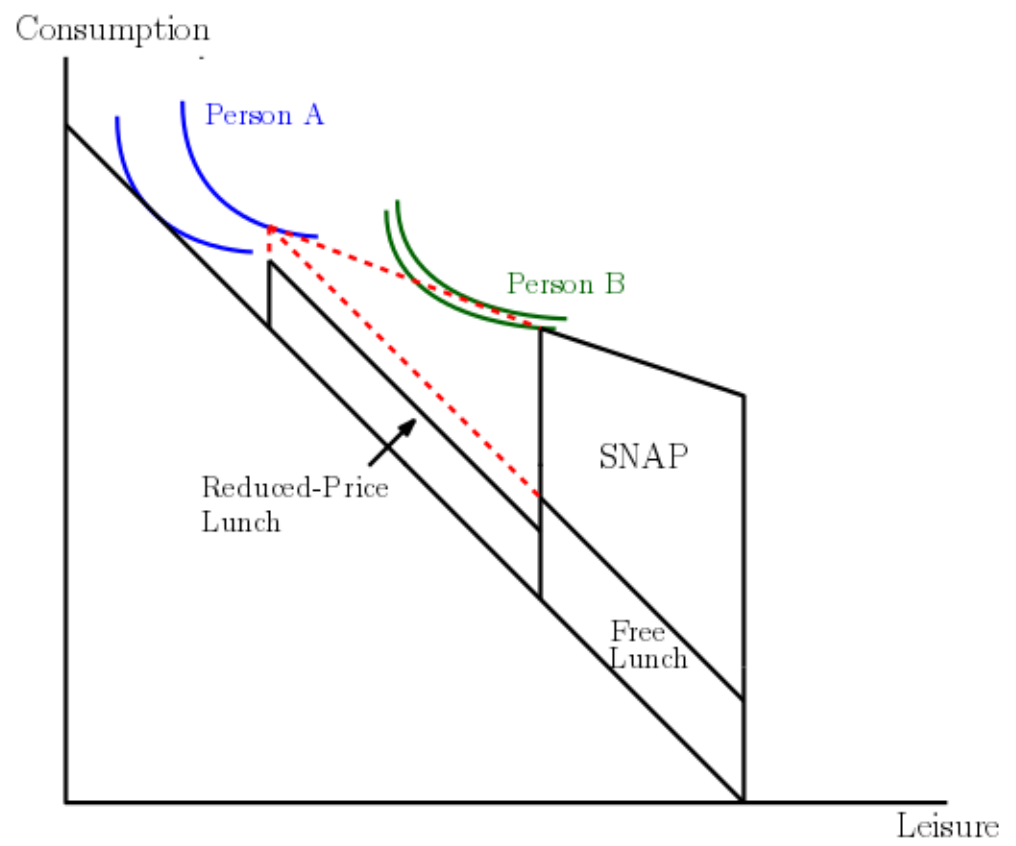

Panel B. Effect of becoming aware of eligibility for Medicaid in the SNAP application process

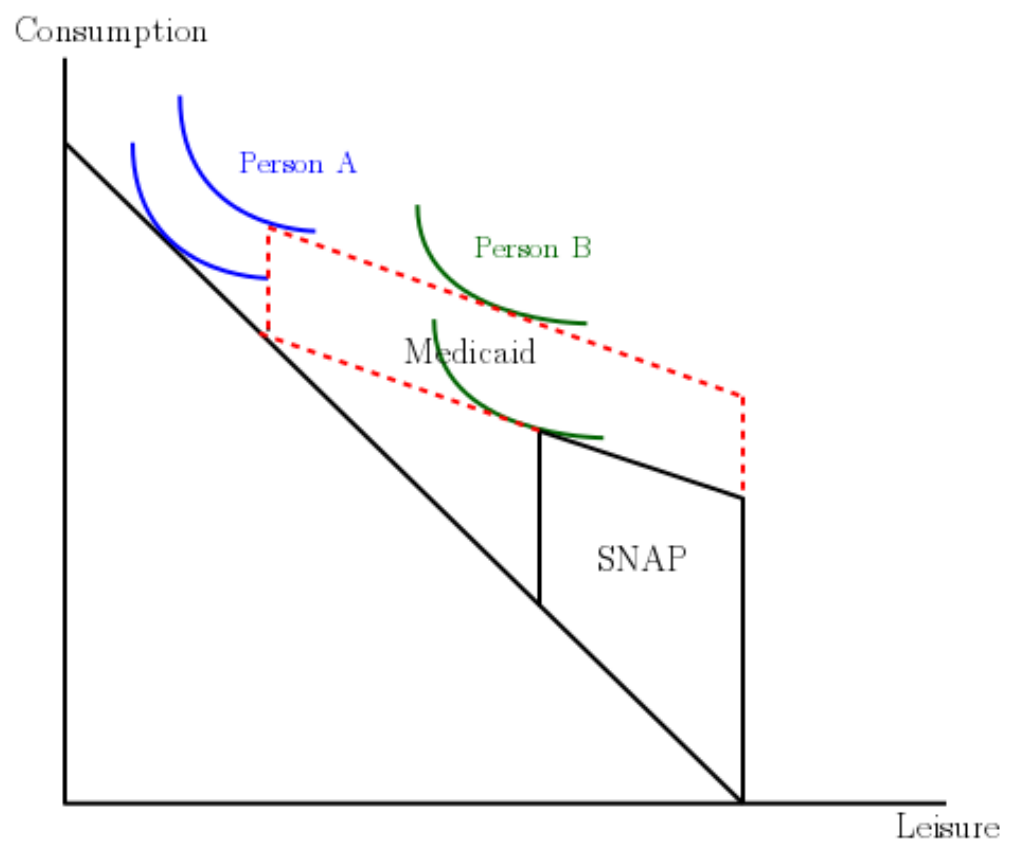




\section{Appendix Figure 2. Selected BBCE brochures}

Panel A: BBCE brochure in Connecticut

United Way Infoline 2-1-1

2-1-1 provides information and referral services about basic needs (food, clothing and shelter),

child care, energy assistance, disability services,

suicide prevention, senior services, veteran's

services, health services and much more. Available

24 hours, 7 days a week dial 2-1-1 or

visit www. $211 \mathrm{ct}$.org.

Connecticut Energy Assistance Program (CEAP)

CEAP helps households pay for primary heating bills. If your primary heating cost is included in your rent, you may also apply for CEAP. Visit the website at www.dss.ct.gov/staywarm, or for more website at www.dss.ct.gov/staywarm, or for more

Family Planning and Pregnancy Prevention For information about family planning call Planne Parenthood at 1-800-230-PLAN, the Connecticut Department of Public Health at 860-509-8000, dial 2-1-1. You can also visit the University of Connecticut teen pregnancy prevention website at: www.teenpregnancy-ct.org

Free Tax Preparation Services

From January 15 to April 15 each year, the Volunteer Income Tax Assistance (VITA) program offers free tax help to people who make less than $\$ 52,000$ a year need help with their tax returns. For more information about VITA visit http://www.irs.gov/Individuals/Free-Tax-RetumPreparation-for-You-by-Volunteers or dial 2-1-1

Food Banks

Foodshare and the Connecticut Food Bank provide safe and mutritious food to food pantries, soup kitchens and shelters throughout Connecticut. To find a food pantry near you, dial 2-1-1.
For more information visit the DSS website at www.ct.gov/dss or dial 2-1-1.

The Department of Social Services does not discriminate on the basis of race, color, religion, sex, gender identity or expression, marital status, age, national origin, ancestry, political beliefs, sexual orientation, intellectual disability, mental disability, learning disability or physical disability, including, but not limited to, blindness. Deaf and hearing impaired persons may use a TDD/TTY by calling 1-800 842-4524. Auxiliary aids are also available for blind or visually impaired persons.

State of Connecticut

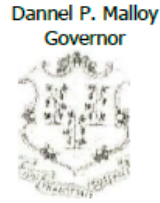

Department of Social Services Roderick L. Bremby Commissioner

This pamphlet is funded by the U.S. Department of Health and Human Services, Temporary Assistance for Needy Families Program.

The Department of Social Services is an equal opportunity, affirmative action employer.

Publication 09-02, revised January 2015

\section{Help for \\ People in Need}

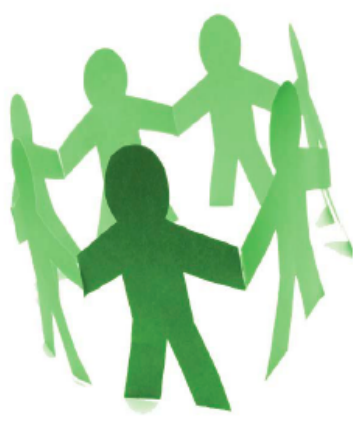

The Department of Social Services, along with other Connecticut agencies and organizations, provide a wide range of programs that may benefit you and your family. 
Panel B: BBCE brochure in Minnesota (page 1 of 4)

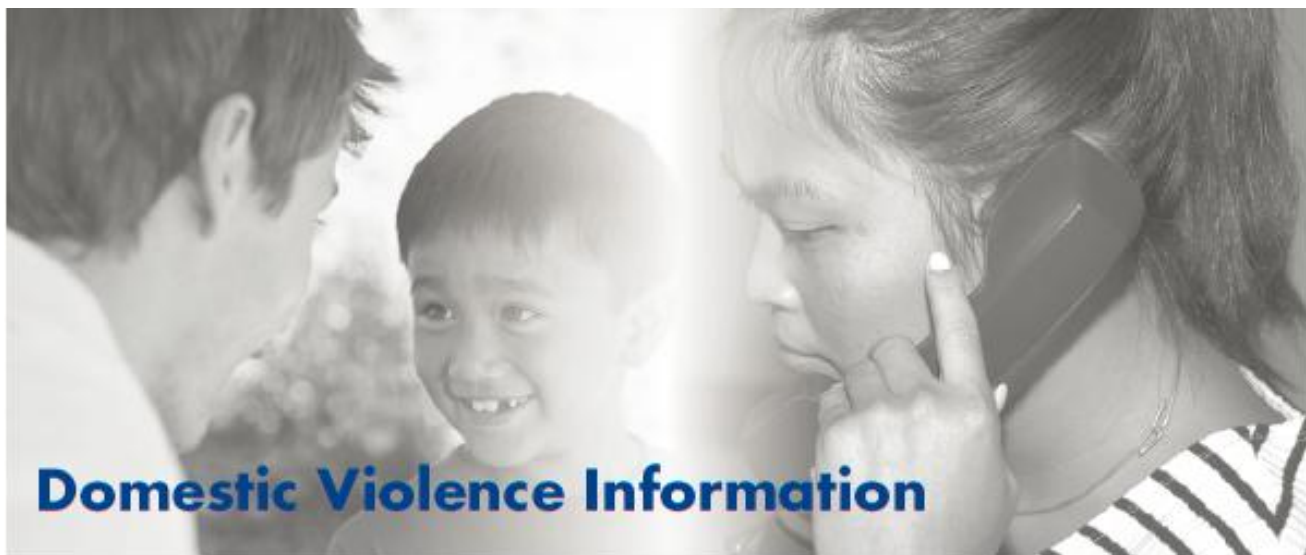

\section{What is domestic violence?}

Domestic violence or abuse is what someone says or does over and over again to make you foel afraid or to control you. Poople who are dderty, frail, have a disability, or who depend on others for assistance may not be able to protect themselves from domertic violence or abuse. Minnesota has a law to protect and assist people who are vulnerable to abuse or who are notable to care for themselves. Examples of violence or abuse include:

- Swearing or screaming at you

- Calling you names

- Taking money or property without permission or against your wishes

- Threatening to hurt you or others you care about

- Failing to provide care for you by so meone whose responsibility it is to do so

- Not letting you leave your house

- Blaming you for everything that goes wrong - Stalking you

- Being touched against your wishes or forced to have sex

- Choking, grabbing, hitting, pushing, pinching or kicking you

What services are available to victims of domestic violence or abuse?

Toll-free Hotlines have counselors who provide services, including:

- Crisis counsd ing

- Safety planning

- Assistance with finding shelter.
Referrals to other organizations induding:

- Legal services support group

- Advocacy with the police.

If you are in danger from domestic violence or abuse and need help, call the National Domestic Violence Hodine at 800-799-7233, (TTY: 800-787-3224), the Minnesota Coalition for Battered Women at 800-289-6177, or the Minnesota Day One Emergency Shelter and Crisis Hotline at $800-223-1111$.

The Safe At Home (SAH) Program is a statewide address confidentiality program that assists survivors of domestic viol ence, sexual assault, stalking a nd others who fear for their safety by providing a substitute address for people who move or are about to move to a new location unknown to their aggressors. For information on this program, contact Safe At Home at 651-201-1399 or 866-723-3035.

\section{Vulnerable adults}

Call the Senior LinkAge Line at 800-333-2433 to report concerns and to help a vulnerable adult get needed protection and assistance. For more information, ask your worker for the "Help protect people whe are frail orvulnerable" brochure (DHS-2754).

What are domestic violence waivers?

If you are digible for public assistance and you experience domestic violence, certain program requirements may not apply in your situation.

Waivers are available for eligible public assi stance applicants who apply for the following programs: Supplemental Nutrition Assistance Program (SNAP), General Assistance (GA), Diversionary Work Program (DWP), Minnesota Family Investment Program (MFIP), Medical Assistance and MinnesotaCare.

If domestic violence or abuse makes it hard for you to follow program rules, talk to your county worker. 
Appendix Table 1. State's SNAP Eligibility Criteria and Provision of WIC/NSLP Information as of June 2013

\begin{tabular}{|c|c|c|c|c|c|c|c|c|}
\hline State & $\begin{array}{l}\text { BBCE } \\
\text { status }\end{array}$ & $\begin{array}{c}\text { Gross } \\
\text { Income } \\
\text { Limits }\end{array}$ & $\begin{array}{l}\text { Net Income } \\
\text { Limits }\end{array}$ & Asset Test & $\begin{array}{l}\text { Year of } \\
\text { BBCE }\end{array}$ & $\begin{array}{l}\text { Type of BBCE } \\
\text { Information }\end{array}$ & $\begin{array}{l}\text { Provision of } \\
\text { Info. on WIC }\end{array}$ & $\begin{array}{l}\text { Provision of } \\
\text { Info. on } \\
\text { School lunch }\end{array}$ \\
\hline $\mathrm{AL}$ & $Y$ & $130 \%$ & $130 \%$ & $\mathrm{~N}$ & 2010 & Brochure & & \\
\hline$A K$ & $\mathrm{~N}$ & $130 \%$ & $100 \%$ & $Y$ & & & & \\
\hline$A Z$ & Y & $185 \%$ & $185 \%$ & $\mathrm{~N}$ & 2007 & Info. on app. & & 0 \\
\hline$A R$ & $\mathrm{~N}$ & $130 \%$ & $100 \%$ & Y & & & & \\
\hline $\mathrm{CA}$ & Y & $130 \%$ & $130 \%$ & $\mathrm{~N}$ & 2009 & Brochure & 0 & \\
\hline $\mathrm{CO}$ & Y & $130 \%$ & $100 \%$ & $\mathrm{~N}$ & 2011 & Info. on app. & & \\
\hline CT & Y & $185 \%$ & $185 \%$ & $\mathrm{~N}$ & 2009 & Brochure & 0 & 0 \\
\hline DE & $Y$ & $200 \%$ & $200 \%$ & $\mathrm{~N}$ & 2000 & Info. on app. & & \\
\hline DC & Y & $200 \%$ & $200 \%$ & $\mathrm{~N}$ & 2010 & Brochure & 0 & \\
\hline $\mathrm{FL}$ & Y & $200 \%$ & $200 \%$ & $\mathrm{~N}$ & 2010 & Referral info. & & \\
\hline $\mathrm{GA}$ & Y & $130 \%$ & $130 \%$ & $\mathrm{~N}$ & 2008 & Brochure & 0 & \\
\hline $\mathrm{HI}$ & Y & $200 \%$ & $200 \%$ & $\mathrm{~N}$ & 2010 & Brochure & & 0 \\
\hline ID & $Y$ & $130 \%$ & $100 \%$ & Y & 2009 & Brochure & & \\
\hline IL & Y & $130 \%$ & $130 \%$ & $\mathrm{~N}$ & 2010 & Brochure & $\mathrm{O}$ & \\
\hline IN & $\mathrm{N}$ & $130 \%$ & $100 \%$ & Y & & & & \\
\hline IA & Y & $160 \%$ & $160 \%$ & $\mathrm{~N}$ & 2010 & Referral info. & $\mathrm{O}$ & \\
\hline KS & $\mathrm{N}$ & $130 \%$ & $100 \%$ & Y & & & & \\
\hline KY & Y & $130 \%$ & $130 \%$ & $\mathrm{~N}$ & 2010 & Brochure & & \\
\hline LA & Y & $130 \%$ & $100 \%$ & $\mathrm{~N}$ & 2010 & Brochure & & \\
\hline $\mathrm{ME}$ & Y & $185 \%$ & $185 \%$ & $\mathrm{~N}$ & 2000 & Brochure & & \\
\hline $\mathrm{MD}$ & Y & $200 \%$ & $200 \%$ & $\mathrm{~N}$ & 2001 & Brochure & & \\
\hline MA & Y & $200 \%$ & $200 \%$ & $\mathrm{~N}$ & 2001 & Brochure & $\mathrm{O}$ & 0 \\
\hline $\mathrm{MI}$ & Y & $200 \%$ & $200 \%$ & Y & 2000 & Info. on app. & $\mathrm{O}$ & \\
\hline $\mathrm{MN}$ & Y & $165 \%$ & $165 \%$ & $\mathrm{~N}$ & 2006 & Brochure & & \\
\hline MS & Y & $130 \%$ & $100 \%$ & $\mathrm{~N}$ & 2010 & Info. on app. & & \\
\hline MO & $\mathrm{N}$ & $130 \%$ & $100 \%$ & $Y$ & & & & \\
\hline
\end{tabular}


Appendix Table 1. Continued

\begin{tabular}{|c|c|c|c|c|c|c|c|c|}
\hline MT & $\mathrm{Y}$ & $200 \%$ & $100 \%$ & $\mathrm{~N}$ & 2009 & Brochure & 0 & \\
\hline $\mathrm{NE}$ & $Y$ & $130 \%$ & $100 \%$ & $Y$ & 2011 & Brochure & & \\
\hline NV & $Y$ & $200 \%$ & $200 \%$ & $\mathrm{~N}$ & 2009 & $\begin{array}{l}\text { Info. on } \\
\text { app. }\end{array}$ & & \\
\hline $\mathrm{NH}$ & Y & $185 \%$ & $185 \%$ & $N$ & 2009 & Brochure & 0 & \\
\hline NJ & $Y$ & $185 \%$ & $185 \%$ & $\mathrm{~N}$ & 2010 & Brochure & & \\
\hline NM & $Y$ & $165 \%$ & $165 \%$ & $\mathrm{~N}$ & 2010 & Brochure & & \\
\hline NY & $\mathrm{Y}$ & $200 \%$ & $200 \%$ & $N$ & 2008 & Brochure & 0 & 0 \\
\hline NC & Y & $200 \%$ & $200 \%$ & $N$ & 2010 & Brochure & & \\
\hline ND & $Y$ & $200 \%$ & $100 \%$ & $\mathrm{~N}$ & 2000 & Brochure & 0 & 0 \\
\hline $\mathrm{OH}$ & $\mathrm{Y}$ & $130 \%$ & $130 \%$ & $\mathrm{~N}$ & 2008 & $\begin{array}{l}\text { Referral } \\
\text { info. }\end{array}$ & & \\
\hline OK & $\mathrm{Y}$ & $130 \%$ & $100 \%$ & $\mathrm{~N}$ & 2009 & $\begin{array}{l}\text { Referral } \\
\text { info. }\end{array}$ & & \\
\hline OR & Y & $185 \%$ & $185 \%$ & $\mathrm{~N}$ & 2000 & Brochure & 0 & $\mathrm{O}$ \\
\hline PA & $Y$ & $165 \%$ & $165 \%$ & Y & 2008 & Brochure & 0 & $\mathrm{O}$ \\
\hline RI & $Y$ & $185 \%$ & $185 \%$ & $\mathrm{~N}$ & 2009 & Brochure & 0 & $\mathrm{O}$ \\
\hline SC & $Y$ & $130 \%$ & $130 \%$ & $\mathrm{~N}$ & 2001 & Brochure & 0 & \\
\hline SD & $\mathrm{N}$ & $130 \%$ & $100 \%$ & $Y$ & & & & \\
\hline $\mathrm{TN}$ & $\mathrm{N}$ & $130 \%$ & $100 \%$ & $Y$ & & & & \\
\hline $\mathrm{TX}$ & $\mathrm{Y}$ & $165 \%$ & $165 \%$ & $Y$ & 2001 & $\begin{array}{l}\text { Info. on } \\
\text { app. }\end{array}$ & 0 & \\
\hline UT & $\mathrm{N}$ & $130 \%$ & $100 \%$ & $Y$ & & & 0 & \\
\hline VT & $\mathrm{Y}$ & $185 \%$ & $185 \%$ & $\mathrm{~N}$ & 2009 & $\begin{array}{l}\text { Referral } \\
\text { info. }\end{array}$ & 0 & $\mathrm{O}$ \\
\hline VA & $\mathrm{N}$ & $130 \%$ & $100 \%$ & $Y$ & & & & \\
\hline WA & $Y$ & $200 \%$ & $200 \%$ & $\mathrm{~N}$ & 2004 & $\begin{array}{l}\text { Referral } \\
\text { info. }\end{array}$ & & \\
\hline WV & $\mathrm{Y}$ & $130 \%$ & $130 \%$ & $N$ & 2008 & Brochure & 0 & \\
\hline WI & $Y$ & $200 \%$ & $200 \%$ & $\mathrm{~N}$ & 2004 & $\begin{array}{l}\text { Referral } \\
\text { info. }\end{array}$ & & \\
\hline$W Y$ & $\mathrm{~N}$ & $130 \%$ & $100 \%$ & $Y$ & & & & \\
\hline
\end{tabular}

Note: All eligibility limits are for households with children. WIC/NSLP information provision status is based on BBCE brochures and SNAP application forms. Data on SNAP eligibility limits are from the Economic Research Service's SNAP Policy Database (http://www.ers.usda.gov/data-products/snap-policy-database.aspx) and Laird and Trippe (2014). BBCE brochures and SNAP application forms are collected from Trippe and Gillooly (2010), Laird and Trippe (2014), contact with state SNAP offices, and internet searches. 
Appendix Table 2. The Effect of SNAP Expansions on Labor Supply, Alternative Sample

\begin{tabular}{lcccc}
\hline \hline Dependent Variable & $\begin{array}{c}\text { Head } \\
\text { Employed }\end{array}$ & Head Hours & $\begin{array}{c}\text { Head Hours } \\
\text { if Emp. }\end{array}$ & $\begin{array}{c}\text { Head } \\
\text { Earnings }\end{array}$ \\
\hline Estimation Framework: DD & & & & \\
Simulated Eligibility & -0.022 & 0.558 & $1.654^{* *}$ & -6.527 \\
& $(0.020)$ & $(0.894)$ & $(0.796)$ & $(73.740)$ \\
Mean of Dep. Var & 0.79 & 30.74 & 38.9 & 1598.3 \\
N & 22,286 & 22,286 & 17,279 & 22,286 \\
\hline
\end{tabular}

Notes: Data are from SIPP 1997-2013. The table reports estimates from equation (2) on samples of households with children and gross income $100 \%-200 \%$ FPL where gross income is calculated as the average income over the first four months of the 12 reference months, and outcome variables are constructed based on data in the remaining 8 months. For example, the outcome variable in column 1 is an indicator for whether a household head was ever employed for the last 8 months. All specifications include demographic controls listed in Table 1, imputed Medicaid/CHIP eligibility, year FE, state $\mathrm{FE}$, and state characteristics such as the state unemployment rates, 1 and 2-year lags in the state unemployment rates, the state poverty rates, minimum wage, TANF maximum benefit levels, EITC parameters, and other changes in SNAP beside BBCE listed in footnote 11. All dollar amounts are in 2010 dollars. Estimates are weighted using the household weights and robust standard errors clustered at the state level in parentheses. ${ }^{* * *} 0.01, * * 0.05, * 0.1$. 


\section{Methods Appendix}

A. Construction of the main sample

To construct the main sample of my analysis (households with children and gross income 100-200\% FPL), I combine three waves together in a SIPP panel where each wave consists of 4 months. For example, in the 2001 SIPP panel, I combine waves 1-3, 4-6, and 7-9, respectively, to construct the samples in the years 2001, 2002, and 2003. Note that each wave consists of four subsamples (rotation groups), which have different reference periods. For example, some households from the waves 1-3 of Panel 2001 have a reference period from Oct 2000 to Sep 2001, while other households' reference periods are from Jan 2001 to Dec 2001. Therefore, many households' reference periods do not exactly match a calendar year. I simply treat all households from waves 1-3 of Panel 2001 as a sample in 2001 to avoid losing many observations. ${ }^{27}$ To measure the gross income for each household, I take an average of monthly gross income in the past 12 months (households with incomplete income information for the past 12 months are excluded from the sample). Based on this measure of gross income and the demographic information in the last month of the 12 month reference period, I restrict the sample to households with children (age<18) and gross income between 100-200\% FPL.

\section{B. Construction of the simulated eligibility measure}

The simulated eligibility measure is based on estimates of the number of households that are eligible under the federal SNAP rules, the number of household that is eligible under the most extensive BBCE rules, and the number of households eligible under the SNAP rules for a given state and month. To identify households that are income and asset eligible for federal and state SNAP rules, I first establish a baseline sample in each year by combining three core wave files with the corresponding topical module on assets in a SIPP panel. For example, to construct the sample for the year 2003, the asset topical module of the 2001 SIPP wave 6 is merged to the core data from waves 4-6 in the 2001 SIPP. Using this sample, I estimate monthly gross and net income, and countable assets for each household as follows:

Gross income. To measure the gross income for each household, I take an average of monthly gross income in the past 12 months. Household monthly earned income, which is used to calculate the net income, is measured in this same way. Households with incomplete income information for the past 12 months are excluded from the sample.

\footnotetext{
${ }^{27}$ Using a similar way, I combine waves 4-6, 7-9, 10-12 of Panel 1996, waves 1-3, 4-6, 7-9, 10-12 of Panel 2004, and waves 2-4, 5-7, 8-10, 11-13, 14-16 of Panel 2008 in order to construct samples in the years 1997-1999, 20042007, and 2009-2013, respectively.
} 
Net income. The net income of a household is calculated by subtracting the excess shelter costs from the adjusted income where adjusted income and excess shelter costs are calculated as:

adjusted income $=$ gross income $-20 \%$ of earned income - standard deduction - out-of-pocket medical cost over $\$ 35$ for elderly and disabled members - child care costs - child support costs

excess shelter costs $=\max (0$, shelter costs - adjusted income/2 $))$

where the standard deduction applies to all households and varies with household size. There is a limit on the excess shelter cost deduction (e.g., \$367 in 2003) unless the household has an elderly or disabled member (http://www.fns.usda.gov/snap/eligibility).

Assets. A household's countable assets are calculated as:

Countable assets $=$ assets in bank + assets in other institutes + assets in stocks + real estate other than home + other assets + vehicle assets

States have different rules in counting the value of vehicles. Under the federal rules, for instance, the fair market value (FMV) over $\$ 4,650$ or the equity value, whichever is more, is counted toward countable assets. $^{28}$

This household income and asset information is then used to construct a sample of households that are eligible under the most extensive BBCE rules (gross income below 200\% FPL), but ineligible for the federal rules (households with gross income below 130\% FPL, net income below 100\% FPL, and countable assets below $\$ 2,250^{29}$ ) for each year. Lastly, the fraction of this sample that is eligible under the SNAP rules for each state and month, representing simulated eligibility, is assigned to households in the relevant state and month.

\footnotetext{
${ }^{28}$ Vehicles with equity less than $\$ 1,500$, vehicles used as a home, vehicles used to produce income, and vehicles used to transport disabled household members or fuel and water are not counted. In addition, for one vehicle per adult and any vehicle a teenager drives to work or school, the amount of the FMV over $\$ 4,650$ is counted toward countable assets (i.e., the equity value is not considered). Since the SIPP does not collect data on the driver of a car, I simply count the amount of the FMV over $\$ 4,650$ of as many vehicles as the number of adults in a household, where vehicles are processed in descending order of their FMVs.

${ }^{29}$ For households with an elderly or disabled member, the assets limit is $\$ 3,250$ and there is no gross income limit.
} 